\title{
Disruption of Classical Eyelid Conditioning after Cerebellar Lesions: Damage to a Memory Trace System or a Simple Performance Deficit?
}

\author{
Joseph E. Steinmetz, ${ }^{1}$ David G. Lavond, ${ }^{2}$ Dragana Ivkovich, ${ }^{2}$ Christine G. Logan, ${ }^{2}$ and Richard F. Thompson ${ }^{2}$ \\ 'Department of Psychology and Program in Neural Science, Indiana University, Bloomington, Indiana 47405 and \\ 2Department of Psychology and Neurosciences Program, University of Southern California, Los Angeles, California 90089
}

Over the past 10 years, a number of laboratories have reported that classically conditioned skeletal muscle responses, such as conditioned nictitating membrane/eyelid responses, are critically dependent on activity in the cerebellum. For example, unilateral lesions of the cerebellar interpositus nucleus have been shown to prevent acquisition and abolish retention of the conditioned eyelid response on the side ipsilateral to the lesions without affecting conditioned responding (CR) on the contralateral side. Also, recording studies involving the interpositus nucleus have consistently revealed patterns of neuronal discharge that predict execution of the CR. The lesion and recording studies have generally been cited as evidence that plasticity in the cerebellum is critically involved in the learning and memory of classically conditioned responses. This interpretation was recently challenged by Welsh and Harvey (1989a), who claimed that cerebellar lesions simply produced a performance deficit and speculated that the role of the cerebellum was not in learning and memory processes associated with the CR but only in performance of the eye blink response. Presented here are three experiments that provide additional strong evidence for a critical role of the cerebellum in the learning and memory of the Pavlovian CR. These experiments include (1) demonstrations of complete and permanent CR abolition after appropriate interpositus lesions, (2) a failure to find systematic or persisting decrements in the unconditioned response amplitude (i.e., the eye blink reflex) after appropriate interpositus lesion, and (3) observations of differential effects on the $\mathrm{CR}$ and unconditioned response after lesions were placed in populations of motoneurons responsible for executing the eye blink response. These data are discussed in the context of performance versus learning issues; evidence presented here rules out the possibility that interpositus lesion abolition of the eye blink CR is simply due to lesion effects on performance.

\footnotetext{
Received Feb. 26, 1992; revised June 3, 1992; accepted June 10, 1992

This research was supported by a NIMH Grant (\#MH44052) awarded to J.E.S. and by ONR Contract N00014-91-J-01 12 and grants from the NSF (\#BNS-8117115) and the McKnight Foundation awarded to R.F.T. We thank Sandra S. Steinmetz, Auve Moro, Rosalinda Senoha, Tom Seib, Charlene Huang, and Jin Hun Sohn for technical assistance during these experiments.

Correspondence should be addressed to Joseph E. Steinmetz at the above address.

Copyright (C) 1992 Society for Neuroscience $0270-6474 / 92 / 124403-24 \$ 05.00 / 0$
}

At least two experimental criteria must be met for a brain region to qualify as a putative essential site for the acquisition and subsequent storage of neural plasticity associated with a learned, behavioral response. First, neural recordings taken at the site must show evidence that cells acquire a learning-induced pattern of discharge that could produce the learned behavioral response. Second, destruction of the region must both prevent acquisition and abolish retention of the learned behavioral response without otherwise impairing the response itself, that is, as a reflex response. Using these criteria, a number of brain regions have been studied during classical nictitating membrane (NM)/eyelid conditioning (hereafter termed "eye blink" conditioning) in the hope of identifying brain areas that were involved essentially in this simple form of motor learning. Some brain regions have been found to satisfy the recording criterion. For example, recordings in the pyramidal cell fields of the hippocampus revealed populations of cells that discharged in a manner that predicted the development over trials and execution of classically conditioned responses (c.g., Bcrger and Thompson, 1978). However, lesions placed in brain regions like the hippocampus generally have failed to produce abolition of basic conditioned responding (CR), although response topography, timing, trace conditioning, discrimination reversal, and extinction performance are markedly altered or impaired by hippocampal lesions (Berger and Orr, 1983; Port et al., 1986; Solomon et al., 1986b; Akase et al., 1989), indicating that the hippocampus exerts important actions on the essential CR circuit (Berger et al., 1986).

One brain region that fulfills both the recording and lesion criteria for a putative essential memory trace brain site is the interpositus nucleus of the cerebellum. Recordings from the interpositus nucleus during eye blink conditioning revealed populations of cells that discharged when the conditioning stimuli (CSs) were presented, and, more importantly, populations of cells that also discharged as a result of training just prior to execution of the classically conditioncd response (Foy et al., 1984; McCormick and Thompson, 1984b; Berthier and Moore, 1990). These cells fired in a pattern that was similar to the learned behavioral response; that is, they formed an amplitudetime course "model" of the learned response that preceded and predicted the occurrence of the behavioral CR within trials and over the trials of training. Further, electrical microstimulation of this same region of the interpositus elicited eye blink responses in the untrained animal; that is, the circuit is hard wired from interpositus to behavior (McCormick and Thompson, 1984b; Chapman et al., 1988, 1990). 
We initially reported that lesions of the cerebellum ipsilateral to the trained eye abolished the eye blink $\mathrm{CR}$ completely and selectively, that is, the $\mathrm{CR}$ was completely abolished but the lesion had no effect on the unconditioned response (McCormick et al., 1981, 1982a). The lesions did not prevent learning in the contralateral eye. If the lesion was made before training, animals were completely unable to learn any CRs at all with the eye ipsilateral to the lesion (Lincoln et al., 1982). In other studies, we and others obtained the same results with lesions of the superior cerebellar peduncle, the efferent pathway from interpositus to red nucleus (Lavond et al., 1981; McCormick et al., 1982b; Rosenfield et al., 1985). We then completed a study of effects of electrolytic lesions of the interpositus nucleus ipsilateral to the trained eye (Clark et al., 1984). Results again demonstrated that if the lesions completely destroyed the critical region of the interpositus nucleus, the CR was abolished, with no effect on the unconditioned response (UR). Importantly, if the lesions were incomplete, there was a marked decrease in the amplitude and frequency of occurrence of the $C R$ and a marked increase in $C R$ onset latency. Since electrolytic lesions of the interpositus cause retrograde degeneration in the inferior olive, we made kainic acid lesions of the critical region of the interpositus, with identical results, that is, complete and selective abolition of the CR (Lavond et al., 1985). Yeo et al. (1985a) replicated our interpositus lesion result, using light and white noise CSs and a periorbital shock unconditioned stimulus (US), thus cxtending the gencrality of the findings (we used tone CS and corneal air puff US). We and others have completed a number of subsequent studies showing identical effects of interpositus lesions, that is, complete and selective abolition of the ipsilateral eye blink CR with no effect on the UR (e.g., Lavond et al., 1984a, 1985, 1987; McCormick and Thompson, 1984a; Polenchar et al., 1985; Woodruff-Pak et al., 1985; Yeo et al., 1985a; Steinmetz et al., 1986, 1991; Weisz and LoTurco, 1988; Sears and Steinmetz, 1990a). Reversible "lesions" by microinfusion of nanomolar amounts of neurotransmitter antagonists in the critical region of the interpositus completely and reversibly abolished the CR, with no effect at all on the UR, in a dosedependent fashion (Mamounas et al., 1987). This effect was extremely localized. We have periodically trained and retrained electrolytic interpositus-lesioned animals for periods up to 10 months; no CRs ever developed on the side of the lesion (Lavond et al., 1984a,b; Steinmetz and Steinmetz, 1991; Steinmetz et al., in press).

In related studies, we showed that electrolytic lesions of the critical region of the inferior olive, the face representation in the dorsal accessory olive (DAO), completely prevented learning of the conditioned eye blink response if made before training and resulted in "extinction" and hence abolition of the CR if made after training (McCormick et al., 1985). The lesion had no effect at all on the UR. Again, Yeo et al. (1986) replicated the basic effect; that is, lesions of the DAO abolished the CR. We then made chemical lesions of the DAO, which were in general considerably larger than our electrolytic lesions, and found much more rapid "extinction" and permanent abolition of the contralateral eye blink CR with sparing of the ipsilateral CR (Mintz et al., 1988). Voneida et al. (1990) made chemical lesions of the DAO in cats trained in limb flexion conditioning and found extinction of the CR. There is thus complete agreement that DAO lesions made after training result in abolition of the CR. The only disagreement concerns how rapidly the abolition ("extinction") occurs following lesion; data to date suggest that this may be a function of the size of the lesion and time of initial training postlesion. Finally, in still other related lesion studics, wc and our associatcs have shown that lesions of the middle cerebellar peduncle (conveying mossy fibers to cerebellum) and of appropriate regions of the pontine nuclei cause complete abolition of the CR with no effect on the UR (Solomon et al., 1986a; Lewis et al., 1987; Steinmetz et al., 1987).

In still other related studies, Moore and associates and we showed that lesions of the appropriate region of the magnocellular red nucleus contralateral to the trained eye cause complete abolition of the CR with no effect on the UR (Haley et al., 1983; Rosenfield and Moore, 1983; Rosenfield et al., 1985). Microinfusions of nanomolar amounts of neurotransmitter antagonists in a very localized region of the magnocellular red nucleus reversibly abolished the conditioned eye blink response with no effect on the UR (Haley et al., 1988). Identical results were obtained for the conditioned limb flexion response; appropriate interpositus lesions abolished the conditioned hindlimb flexion response with no effect on reflex flexion in the rabbit (Donegan et al., 1983). Lesions of the red nucleus or descending rubral pathway abolished the conditioned limb flexion response in the cat with no effect on the reflex limb flexion response and no effect on normal behavioral movement control of the limb (Smith, 1970; Tsukahara et al., 1981; Voneida et al., 1990).

All of these data strongly support the hypothesis that the cerebellum and its associated circuitry (pontine nuclei, middle cerebellum peduncle-mossy fibers, inferior olive-climbing fibers, superior cerebellar peduncle, red nucleus, rubral efferents) are a substantial part of the necessary pathways for the conditioned eye blink and limb flexion responses. Further, extensive neuronal unit recording studies, microstimulation studies, and reversible inactivation studies argue very strongly that this circuitry and its afferent inputs form the essential circuitry for classical conditioning of these responses (see General Discussion).

Recently, Welsh and Harvey (1989a) claimed to have obtained results inconsistent with all the interpositus lesion studics citcd above. Specifically, they reported that with extensive pre- and postoperative training, electrolytic interpositus lesions resulted in a very small residual $C R$ with very low amplitude, low frequency of occurrence, and long onset latency, the exact result we reported much earlier to occur with substantial but incomplete electrolytic lesions of the critical region of the interpositus nucleus (Clark et al., 1984). The other result they reported is that the "effective" interpositus lesion results in a very small effect on UR topography at low US intensities.

From these results, Welsh and Harvey concluded that the cerebellum is involved simply in the performance of the conditioned eye blink response and not in learning and memory of the response. The interpositus lesion abolition of the eye blink $\mathrm{CR}$ is the only instance in the lesion-memory literature where a very small lesion (effective lesion not much larger than a cubic millimeter) (Lavond et al., 1985) completely and permanently abolishes the CR and has no effect on the UR. Such a total and selective lesion abolition of a specific memory thus assumes great importance viz-à-viz localization of the memory trace. Consequently, it is critically important to evaluate in detail the results and conclusions claimed by Welsh and Harvey. Several series of experiments are presented here. The first series involved assessing the effects of effective interpositus nucleus lesions on CR durnng paired CS-US trials and CS-alone trials with extensive pre- and/or postoperative training under three variations of the eye blink conditioning paradigm: using the 285 msec interstimulus interval (ISI) and the long CS-alone trial 
observation period employed by Welsh and Harvey (1989a), using a $250 \mathrm{msec}$ ISI and long CS-alone trial observation period, and using a relatively long ISI $(700 \mathrm{msec})$ during all aspects of training. Other experiments reported here were conducted to study possible changes in the topography of the UR after effective interpositus lesion and, more generally, to evaluate the issue of "performance."

\section{Experiment I. Are There Residual CRs Following Effective Lesions of the Interpositus Nucleus?}

Materials and methods

Subjects. Data from 20 male, New Zealand White rabbits are presented here. One group (P10; see below) was run in R.F.T.'s laboratory at Stanford University; the remaining groups were run in J.E.S.'s laboratory at Indiana University. The rabbits were housed individually, given food and water ad lib, and cared for by the Laboratory Animal Resource staffs at Stanford University and at Indiana University. All experimental procedures were conducted during light portions of $12 \mathrm{hr}: 12 \mathrm{hr}$ light/ dark cycles. All surgical procedures were conducted under aseptic conditions. In addition to the 20 rabbits reported here, lesions were given to 7 additional rabbits. The lesions missed the interpositus nucleus, however, and failed to affect conditioned responding (i.e., prelesion levels of conditioncd rcsponding were present by the 20 th-30th postlesion training trials).

Surgery. Rabbits were anesthetized with a mixture of ketamine ( 60 $\mathrm{mg} / \mathrm{kg}$ ) and xylazine $(6 \mathrm{mg} / \mathrm{kg}$ ) and positioned in a standard rabbit stereotaxic head-holding device so that the surface of the skull at bregma was $1.5 \mathrm{~mm}$ above lambda. In 12 rabbits, lesion electrodes $(00$ stainless steel insect pins with $300-400 \mu \mathrm{m}$ exposed tips) were lowered stereotaxically into the regions of the right and left interpositus nuclei and electrolytic, anodal lesions $(0.5 \mathrm{~mA} \mathrm{DC}$ for $30 \mathrm{sec})$ were placed in each nucleus. Lesion electrodes were positioned using stereotaxic coordinates $(0.5 \mathrm{~mm}$ anterior to lambda, $5.5 \mathrm{~mm}$ lateral to lambda, and $14.5 \mathrm{~mm}$ ventral to lambda) and by recording from electrodes as they were lowered. Using these same methods, four rabbits were given unilateral lesions in the region of the left interpositus nucleus. An additional four rabbits were implanted chronically with lesion electrodes in the region of the left interpositus nucleus. In these rabbits, the lesion electrodes were lowered into the brain then cemented into place with dental acrylic. A head-stage plug assembly that included connections to the lesion electrode and a stainless steel ground screw placed in the skull as well as plugs for devices used in subsequent behavioral training sessions were also attached to the skull with dental acrylic. Following surgery, a 1 week recovery was allowed before behavioral training began.

General procedures. After recovery, all rabbits were placed in standard Plexiglas restraint boxes and placed in a sound-attenuating conditioning chamber for a $1 \mathrm{hr}$ adaption session. Subsequent training sessions involved presentations of a tone $\mathrm{CS}(1 \mathrm{kHz}, 85 \mathrm{~dB}$ SPL $)$ and an air puff US $\left(2.1 \mathrm{~N} / \mathrm{cm}^{2}\right)$. Movements of the NM were monitored by a minitorque potentiometer. The arm of the potentiometer was connected to the NM via a length of thread that was hooked to a small loop of suture placed in the membrane during surgery. The potentiometer and a nozzle that held the air puff hose approximately $4-5 \mathrm{~mm}$ from the cornea of the eye were fitted into a head-mount device that either sat on top of the head (for those animals lesioned during surgery) or were fastened onto the plug assembly placed in the acrylic during surgery (for chronically implanted rabbits). A computer programmed in FORTH and assembler language controlled the delivery of stimuli and collected the behavioral data (Lavond and Steinmetz, 1989a).

Behavioral training. Four different training regimens were used to classically condition the nictitating membrane (NM) response of the 20 rabbits reported here. Rabbits in group $A 12(N=5)$ were given bilateral interpositus lesions, a 1 week recovery period, and then 12 daily training sessions involving the left NM. The training sessions consisted of paired presentation of a tone conditioned stimulus (CS) and air puff unconditioned stimulus (US) presented to the left eye. The tone CS was presented for $350 \mathrm{msec}$ and coterminated with a $100 \mathrm{msec}$ air puff US, thus creating a $250 \mathrm{msec}$ interstimulus interval (ISI). The intertrial interval varied randomly between 20 and $40 \mathrm{sec}$ with a mean of $30 \mathrm{sec}$. Rabbits in group $A 24(N=7)$ were given bilateral interpositus nucleus lesions, a 1 week recovery period, and then 24 daily training sessions involving the left NM. The sessions consisted of paired CS-US trials with a 350 msec tone and a 100 msec coterminating air puff. Rabbits in group P1O $(N=4)$ initially received 10 daily sessions of paired toneair puff trials. The tone CS was presented for $250 \mathrm{msec}$ and then terminated, a $35 \mathrm{msec}$ period was allowed to elapse, and then a $100 \mathrm{msec}$ air puff US was presented (i.e., the time between CS onset and US onset, defined as when the air puff impacted the cornea, was $285 \mathrm{msec}$ ). This training procedure is identical to the procedure used by Welsh and Harvey (1989a). After this initial phase of training, the rabbits were anesthetized lightly with the ketamine/xylazine mixture, and an electrolytic, anodal lesion was placed in the left interpositus nucleus via the previously implanted electrode $(1 \mathrm{~mA} \mathrm{DC}$ for $30 \mathrm{sec}$ ). After a 1 week recovery period, the rabbits were given 24 additional days of paired CS-US training using procedures identical to those followed prior to the lesion. These postlesion training sessions were followed by three training sessions that involved paired tone-air puff presentations to the right NM. Rabbits in group $A 700(N=4)$ were given a left interpositus nucleus lesion and then a 1 wcck recovery period. These animals next received eight left NM training sessions, conditioning was next switched to the right NM for six sessions, and then switched back to the left NM for eight additional sessions. All training sessions for group A700 rabbits involved paired presentations of an $800 \mathrm{msec}$ tone CS and a coterminating $100 \mathrm{msec}$ air puff (i.e., creating a $700 \mathrm{msec}$ ISI).

Rabbits in groups A12 and A24 received 12 blocks of training per session with each block consisting of $1 \mathrm{CS}$-alone presentation followed by 8 paired CS-US presentations (i.e., 108 trials/session). Rabbits in group A700 were also given 12 blocks of training, but each block consisted of 1 CS-alone trial followed by 9 paired CS-US trials (i.e., 120 trials/session). Group P10 rabbits received 66 trials per session divided into 6 blocks of 11 trials each. The first 10 trials were paired CS-US presentations while the 11 th trial was a CS-alone presentation.

Data analysis. Extensions of the NM that were $0.5 \mathrm{~mm}$ or greater were counted as responses on all trials. On paired trials for all groups, CRs were defined as NM responses that occurred after the tone CS onset but before the air puff US onset. On CS-alone trials, CRs were detined as NM responses that occurred during a $2500 \mathrm{msec}$ time period that began with the CS onset (groups A12, A24, and P10) or during a 950 msec period after CS onset (group A700). The $2500 \mathrm{msec}$ observation period on CS-alone trials was included to provide ample opportunity to observe the possible development of the small-amplitude, long-latency responses reported by Welsh and Harvey (1989a) to occur after lesions of the interpositus nucleus. Responses occurring after US onset during paired trials were scored as unconditioned responses (URs). Onset latencies were also calculated for each trial on which a response was observed. The onset latency was defined as the point in time after CS onset when a $0.5 \mathrm{~mm}$ NM extension was first observed (but see group P10 below).

Histology. After the last training session, all rabbits were overdosed with an intravenous injection of pentobarbital and perfused via the ascending aorta with $9 \%$ saline followed by $10 \%$ formalin. The brains were then removed and stored in $10 \%$ formalin for at least 2 weeks. Frozen coronal sections $(80 \mu \mathrm{m}$ thick) were then taken through the cerebellum, mounted on gelatinized slides, and then stained with cresyl violet. The stained sections were then viewed under a microscope and the extent of the lesions assessed by reconstructing the damage on standard coronal drawings of the cerebellum.

\section{Results}

The following data were analyzed statistically with ANOVAs using sessions as a repeated measure. Significant main effects were followed by Tukey's honestly significant differences (HSD) post hoc tests. Both percentages of CRs (\%CR) and CR amplitudes were examined statistically, and identical results were obtained for both measures.

\section{Behavioral data}

Group A12. Figure 1 depicts \%CRs recorded on paired trials (Fig. 1 $A$ ) and on CS-alone test trials (Fig. $1 B$ ) across the $12 \mathrm{~d}$ of acquisition training for group A12 rabbits that followed an interpositus nucleus lesion. The greatest mean \%CRs recorded on paired trials for a session was $4.0 \%$ (session 8 ), while the greatest mean \%CRs recorded on test trials for a session was $9.9 \%$ (sessions 3, 4, and 10). Moreover, no significant changes in $\% \mathrm{CRs}$ were found over the 12 acquisition sessions, thus in- 

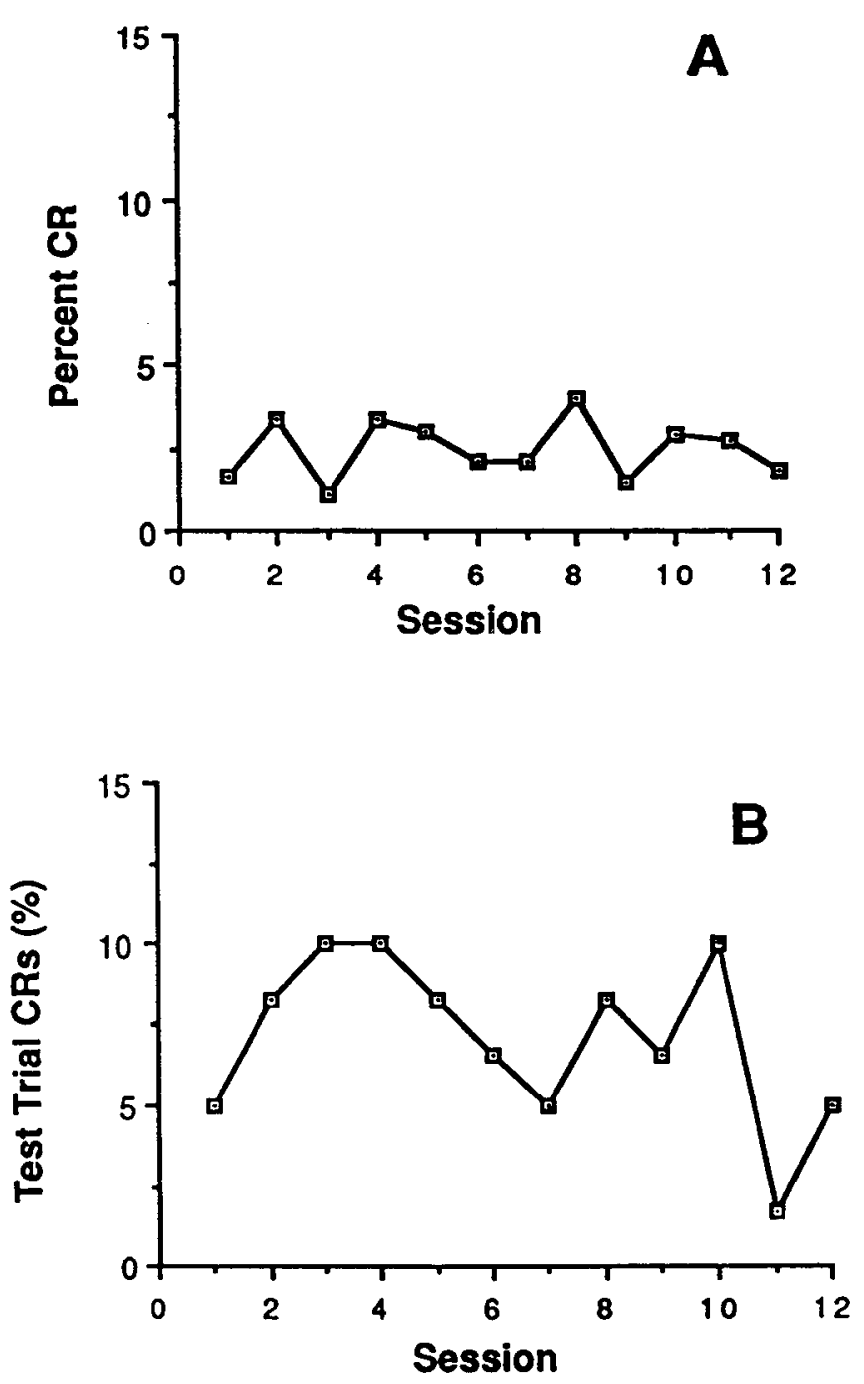

Figure 1. Mean \%CRs recorded on paired CS-US trials $(A)$ and CSalone trials $(B)$ over $12 \mathrm{~d}$ of training that followed interpositus nucleus lesions in group $\mathrm{A} 12$ rabbits.

dicating that the number of CRs emitted on paired or test trials remained steady from the first to the last day of acquisition. It is interesting to note that the observed number of CRs in each session was comparable to the number of responses expected when spontaneous blinking rates are considered. Gormezano et al. (1983) reported that the spontaneous blinking rate for rabbits was about $2-3 \%$ when a $500 \mathrm{msec}$ CS period was examined. Our observation of $4 \%$ responses on paired trials (in a $250 \mathrm{msec}$ period) was close to this spontaneous blink level. Lavond et al. (1987) reported $5 \%$ in a $250 \mathrm{msec}$ baseline period. More importantly, one would expect that 10-15\% spontaneous responses would occur when the $2500 \mathrm{msec}$ observation period was used on test trials (i.e., five times greater than the $500 \mathrm{msec}$ observation period examined by Gormezano and associates). We observed $9.9 \%$ responses on these trials, which is within the spontaneous blinking range. In sum, data from group A12 rabbits failed to show the development of low-amplitude, longlatency responses over $12 \mathrm{~d}$ of acquisition training, and any responses that were observed can be accounted for by spontaneous eye-blinking rates.

Group A24. Figure 2 shows \%CRs recorded on paired trials
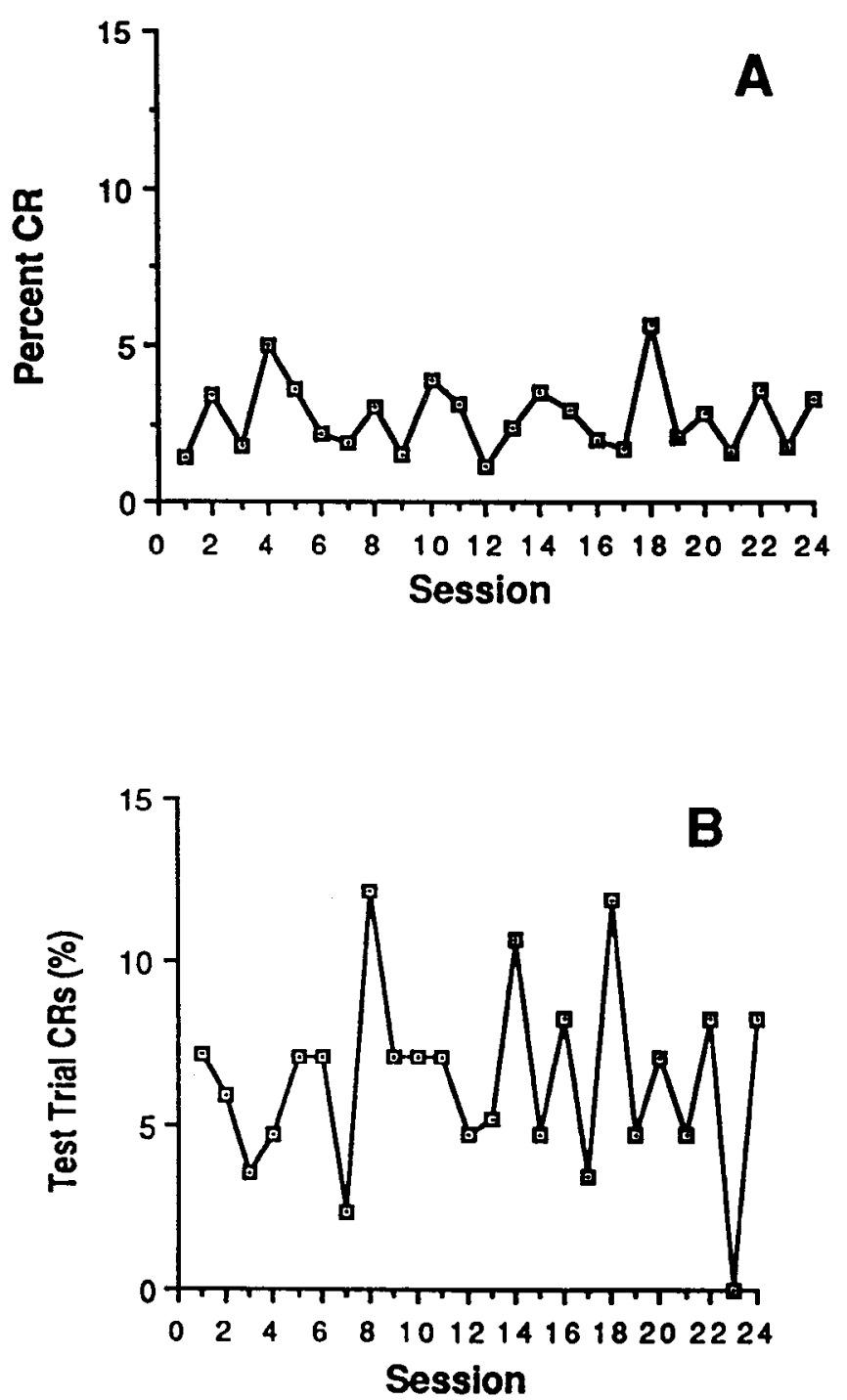

Figure 2. Mean \%CRs recorded on paired CS-US trials $(A)$ and CSalone trials $(B)$ over $24 \mathrm{~d}$ of training that followed interpositus nucleus lesions in group A24 rabbits.

(Fig. $2 A$ ) and CS-alone test trials (Fig. $2 B$ ) over $24 \mathrm{~d}$ of acquisition training that followed an interpositus nucleus lesion (group A24). The maximum \%CRs recorded on paired trials was 5.7\% (session 18), while the maximum \%CRs recorded on test trials was $12.1 \%$ (session 8 ). No significant changes in \%CRs across sessions for paired or test trials could be found, thus indicating that responding did not change significantly between the first and last training sessions. As was the case for group A12 rabbits, the number of CRs emitted was comparable to the expected spontaneous blinking rates when 250 and $2500 \mathrm{msec}$ observation periods were used. The $24 \mathrm{~d}$ of acquisition training in the group afforded a good opportunity to examine onset latencies for the responses that were executed during the $2500 \mathrm{msec}$ test trials observation period. Figure 3 shows a scatterplot of the amplitude and onset latencies of the 123 responses recorded over the $24 \mathrm{~d}$ of acquisition training. This plot shows a clustering of small-amplitude responses (i.e., responses between 0.5 and $1.5 \mathrm{~mm}$ ) with relatively few responses greater than $2.0 \mathrm{~mm}$. However, the figure fails to reveal the high concentration of responses centered around the $349 \mathrm{msec}$ onset latency as re- 


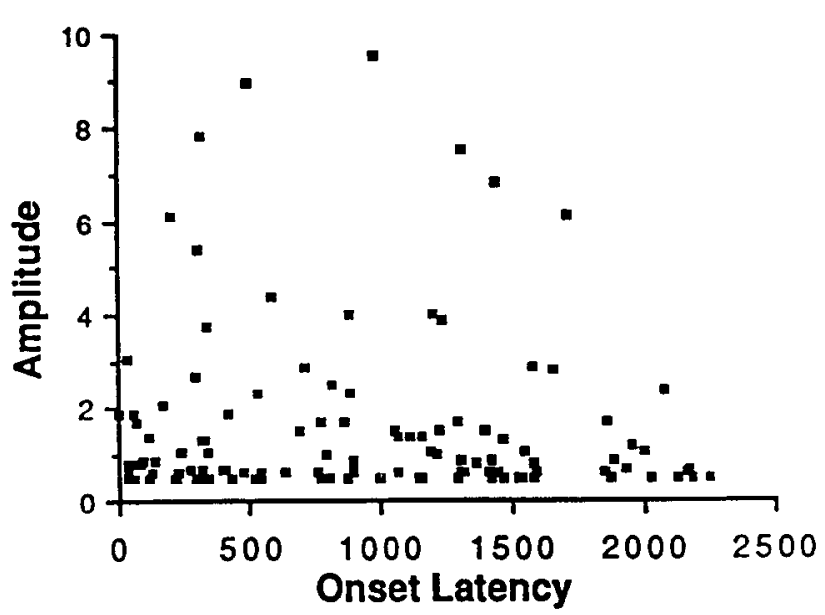

Figure 3. Scatterplot depicting amplitudes and onset latencies of CRs observed during the $2500 \mathrm{msec}$ observation period during CS-alone presentations given to group A24 rabbits.

ported by Welsh and Harvey (1989a). The scatterplot shows relatively uniform distribution of onset responses across the trial period. These data show that the group A24 rabbits executed some small-amplitude responses after the interpositus lesions, but the responses appeared not to be executed at any systematically timed portion of the $2500 \mathrm{msec}$ test trial period. In short, similar to group A12 rabbits, rabbits given $24 \mathrm{~d}$ of acquisition training failed to develop learned responses during the $2500 \mathrm{msec}$ period that followed CS presentation but did execute the expected number of low-amplitude, spontaneous eye blinks during the extended observation period.

Group P10. \%CRs recorded on paired trials and CS-alone test trials for group P10 rabbits are shown in Figure 4, $A$ and $B$. ANOVAs of data collected on paired trials revealed a significant acquisition effect over the $10 \mathrm{~d}$ of training with significant increases in \%CRs present between sessions 1 and 6 ( $p$ values < 0.01 ). No significant changes in \%CRs occurred between sessions 6 and 10. Although not shown in Figure 4, rapid and significant acquisition of CRs occurred when training was switched to the right eye (e.g., the rabbits were showing $91 \%$ CRs by the third day of right-eye training). This finding indicates that the postlesion abolition of CRs in group P10 was not due to some nonspecific reduction in responding. Identical results were obtained when test trials were analyzed. A significant decrease in responding did occur after the interpositus nucleus lesion as $\%$ CRs decreased from $87.5 \%$ to $0.8 \%$ on paired trials and $93.8 \%$ to $4.2 \%$ on CS-alone test trials ( $p$ values $<0.001$ ). No significant increases in \%CRs, on paired or test trials, were observed over the $24 \mathrm{~d}$ of postlesion training. The maximum \%CRs over the 285 msec observation period for paired trials was $5.3 \%$ (session 14), while the maximum \%CRs seen over the $2500 \mathrm{msec}$ observation period for test trials was $12.5 \%$ (sessions 15,28 , and 34). As was the case for groups A12 and A24, these levels of responding are comparable to the spontaneous blinking rate of rabbits (see above). Figure 5 shows a scatterplot of amplitudes and onset latencies of 25 test trial responses observed over the $24 \mathrm{~d}$ of postlesion training. The distribution of response onset latencies for these animals was further analyzed using the same procedure used by Welsh and Harvey, namely, identifying responses that exceeded $0.5 \mathrm{~mm}$ amplitude, measuring backward to a $100 \mu \mathrm{m}$ amplitude, and using this time point as the
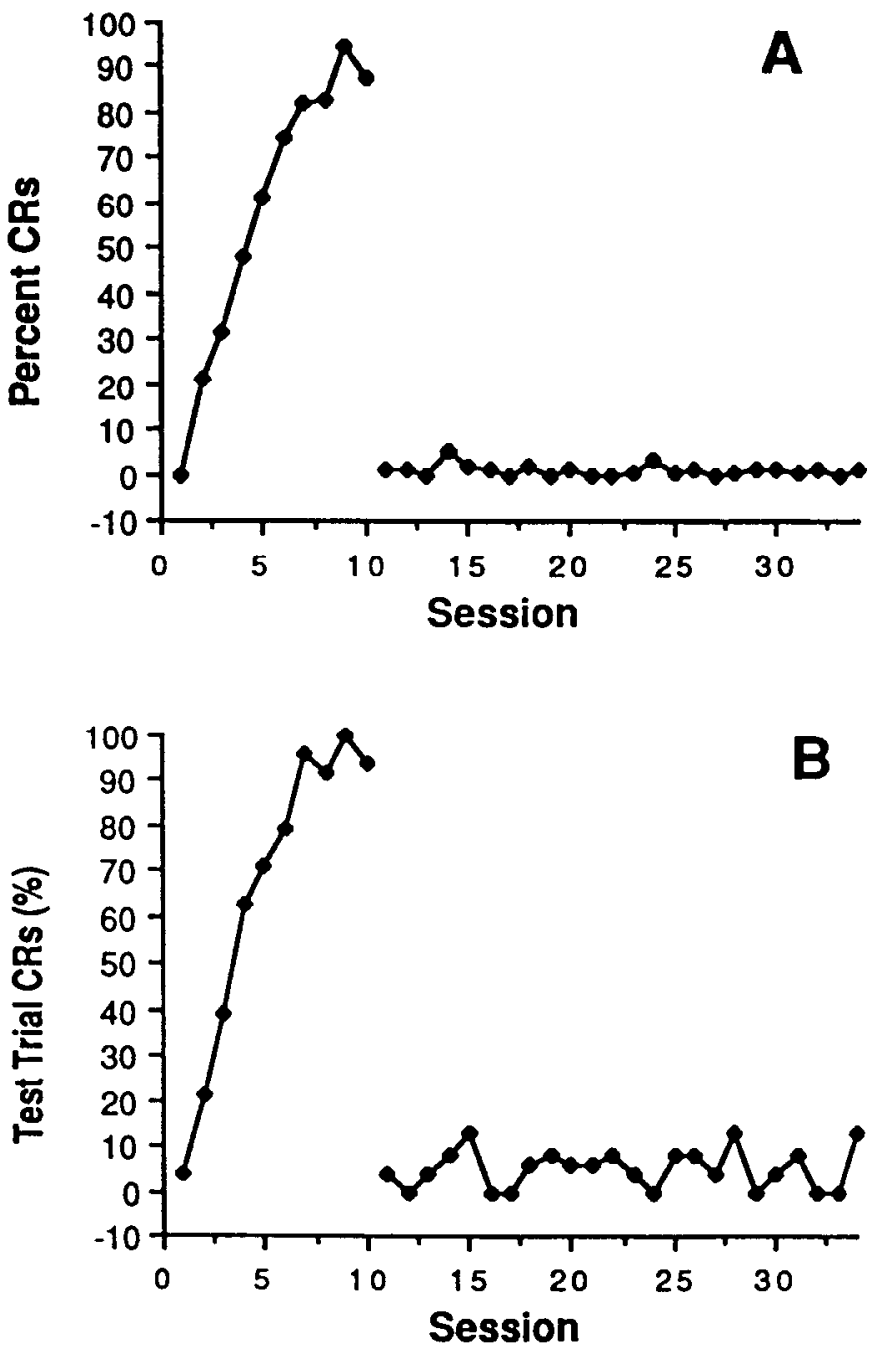

Figure 4. Mean \%CRs recorded from group P10 during 10 prelesion training sessions (sessions 1-10) that were followed by 24 post-interpositus-lesion sessions (sessions 11-34). A, Mean \%CRs on paired CSUS trials. $B$, Mean \%CRs on CS-alone trials.

onset latency. Results of this analysis are identical to those in Figure 5; there is no tendency for these response latencies to cluster around the $348 \mathrm{msec}$ onset latency, or any other time point. In short, no small-amplitude, long-latency CRs develop, a result contradictory to the results reported by Welsh and Harvey.

Group A700. Figure 6, $A$ and $B$, shows \%CRs recorded on paired and CS-alone test trials over $22 \mathrm{~d}$ of NM conditioning for group A700 that received unilateral (left side) interpositus lesions. On paired trials delivered to the left NM, no significant acquisition effect was noted over the first $8 \mathrm{~d}$ of training. The maximum \%CRs was $6.4 \%$ (session 8 ). Significant acquisition effects were noted when training was shifted to the right NM ( $p$ $<0.01$ ), and rabbits showed $87.3 \%$ CRs by session 14 . Analysis of the final $8 \mathrm{~d}$ of left NM conditioning showed no significant changes in \%CRs, with the greatest responding observed on session 21 (6.5\%). Statistical analyses of test trial data produced similar results. The greatest \%CRs recorded during the initial 8 $\mathrm{d}$ of left NM training, $6 \mathrm{~d}$ of right NM training, and 8 final days of left NM training were, respectively, 5.8\% (session 8 ), $83.4 \%$ (session 14), and $8.3 \%$ (session 21 ). The values recorded on left- 


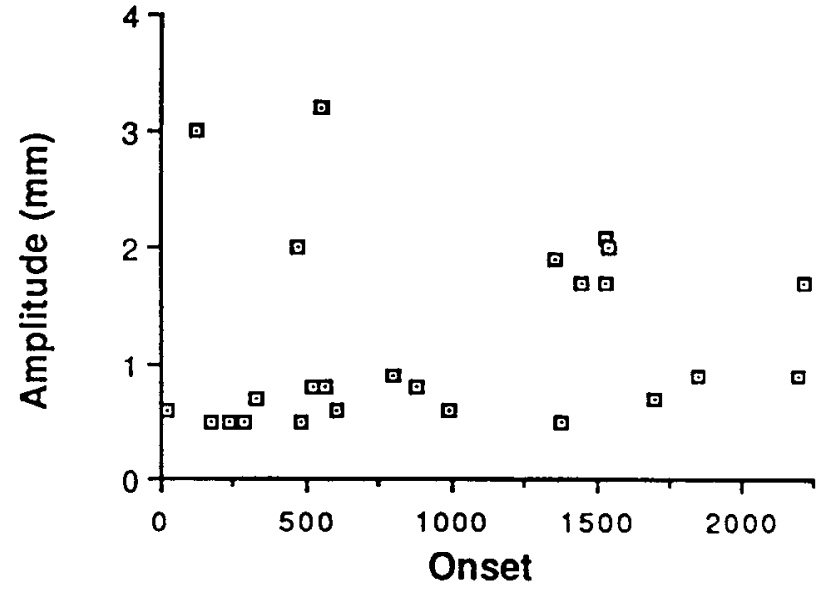

Figure 5. Scatterplot depicting response amplitudes and onset latencies recorded during CS-alone trials given after interpositus lesions in group P10 rabbits.

side (i.e., lesioned) training days are not significantly greater than the 4-6\% rate of responding that can be accounted for by spontaneous eye blinking. It should be noted that if a general performance deficit were caused by the interpositus lesion, a deficit that simply slowed execution of the CR rather than impairing a site of plasticity associated with conditioned responding, one would predict that responses would appear during the ISI because enough time was allowed for the impaired response to be executed (i.e., $700 \mathrm{msec}$ instead of 250 or $285 \mathrm{msec}$ ). This did not occur. In fact, the level of responding in the ISI was similar to that reported for groups A12, A24, and P10. Again, as above, the $\mathrm{A} 700$ data failed to demonstrate the development of the small-amplitude, long-latency responses reported by Welsh and Harvey.

\section{Lesion siles}

Schematic diagrams of the histological reconstructions of the largest and smallest lesion sites for each group are found in Figure 7. The effective lesion sites included dorsolateral portions of the anterior interpositus nucleus, slight portions of the dentate nucleus, and sometimes the white matter overlying the deep cerebellar nuclei.'

\section{Experiment I discussion}

Our lesion results are unambiguous. Not a single one of the 20 animals reported here shows any evidence of CRs following interpositus lcsion. Thrce of these groups were trained extensively after lesion, and one group (P10) was trained extensively before and after lesion. This last group was trained using the exact paradigm of Welsh and Harvey (1989a). Test trial responses were measured for $2500 \mathrm{msec}$ following CS onset. Spontaneous responses were seen in all groups at exactly the levels predicted by the original studies of Gormezano and associates (1983; A12, $2500 \mathrm{msec}, 9.9 \%$; A24, $2500 \mathrm{msec}, 12.1 \%$; P10, $2500 \mathrm{msec}, 12.5 \%$; A700, $950 \mathrm{msec}, 6.4 \%$ ). There was no tendency for these responses to cluster around any time period; they were distributed randomly over the time period following CS onset in all animals (see Fig. 3). Furthermore, the levels of spontaneous responding did not change over days of training. An additional eight animals were trained, given interpositus

\footnotetext{
' Individual histological reconstructions of all lesions are available upon request.
}
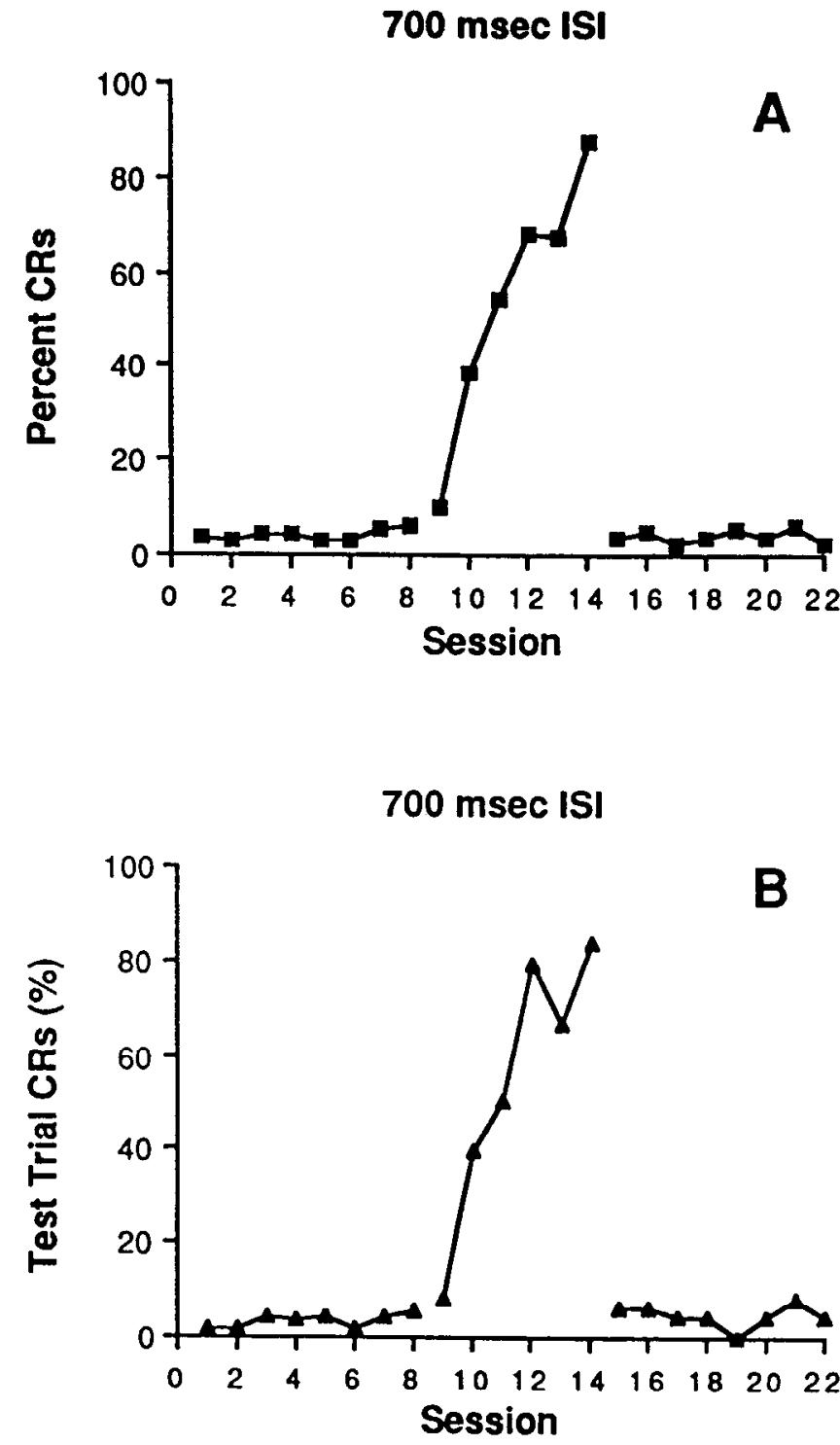

Figure 6. Mean \%CRs recorded during paired CS-US trials $(A)$ and CS-alone trials $(B)$ for group A700 rabbits. These rabbits were given left interpositus nucleus lesions, $8 \mathrm{~d}$ of left-side training (sessions $1-8$ ), $6 \mathrm{~d}$ of right-side training (sessions 9-14), and 8 additional days of leftside training (sessions 15-22).

lesions, and retrained, with identical results, in experiment II (see below). Thus, interpositus lesions made before training completely and permanently prevented learning of the $C R$ and completely and permanently abolished the previously learned CR.

It is to be stressed that four of the "effective" lesion animals in the Welsh and Harvey report were in fact completely effective; these animals did not show any CRs above spontaneous rate in the CS-alone $800 \mathrm{msec}$ test trials over the 12 postoperative sessions. Lesions were not completely effective in the remaining 11 animals; they showed small, residual, longer-latency responses. This is precisely what we reported in our original interpositus lesion study: if the lesion was not completely effective, it caused a marked reduction in amplitude and frequency of CRs and an increase in CR onset latencies (Clark et al., 1984). Examination of reconstructions of 12 of the Welsh and Harvey "effective" lesions (as presented in Welsh, 1987) indicates that 


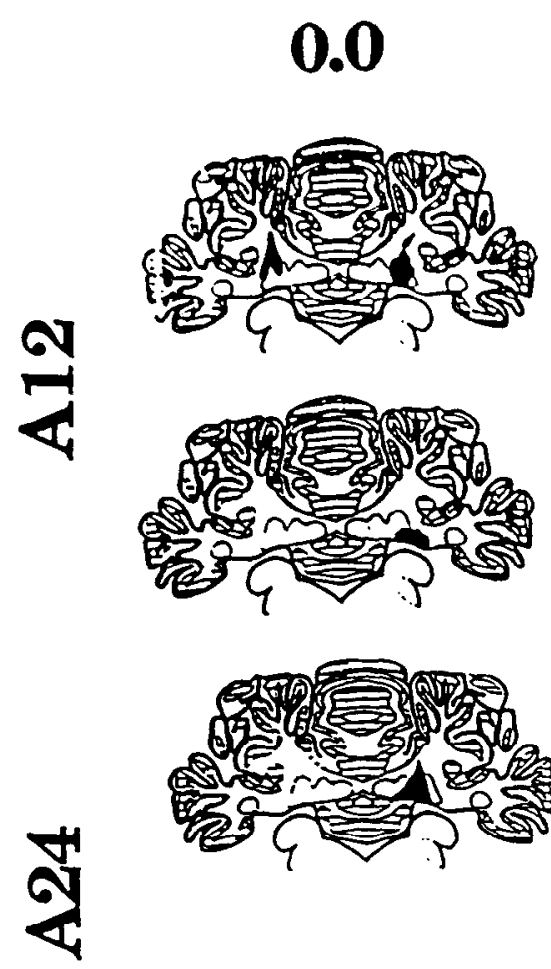

$+0.5$
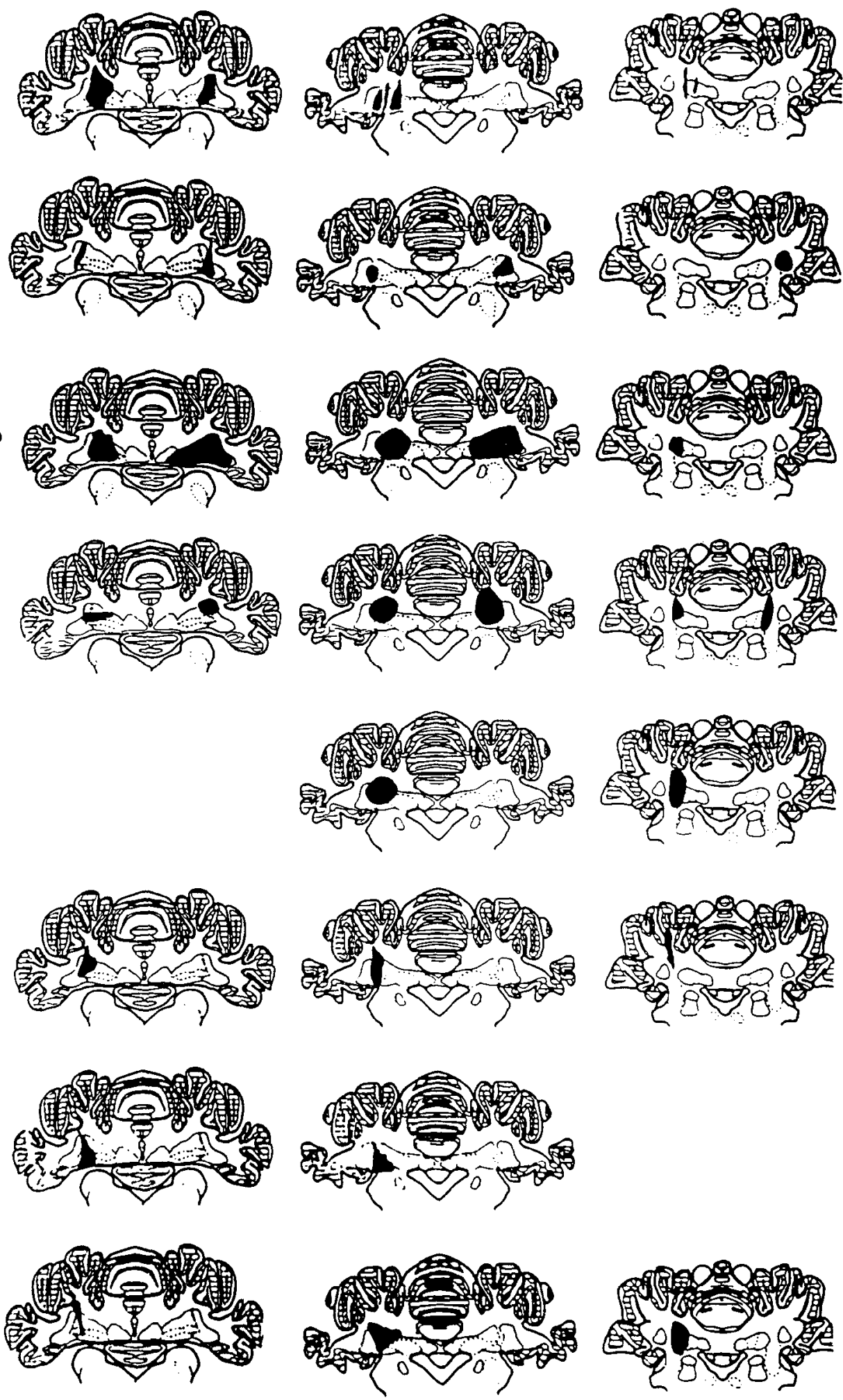

Figure 7. Schematic drawings of coronal brain sections taken though the cerebellum depicting representative lesions given to rabbits in groups $\mathrm{A} 12, \mathrm{~A} 24, \mathrm{P} 10$, and A700. The numbers at the top indicate the distance (in millimeters) from the lambda skull landmark that each section represents. Four sets of drawings are shown (one each for the four groups of lesioned rabbits). The upper drawing of each pair shows the extent of the largest lesion observed in each group while the lower drawing of each pair shows the extent of the smallest lesion in each group. 


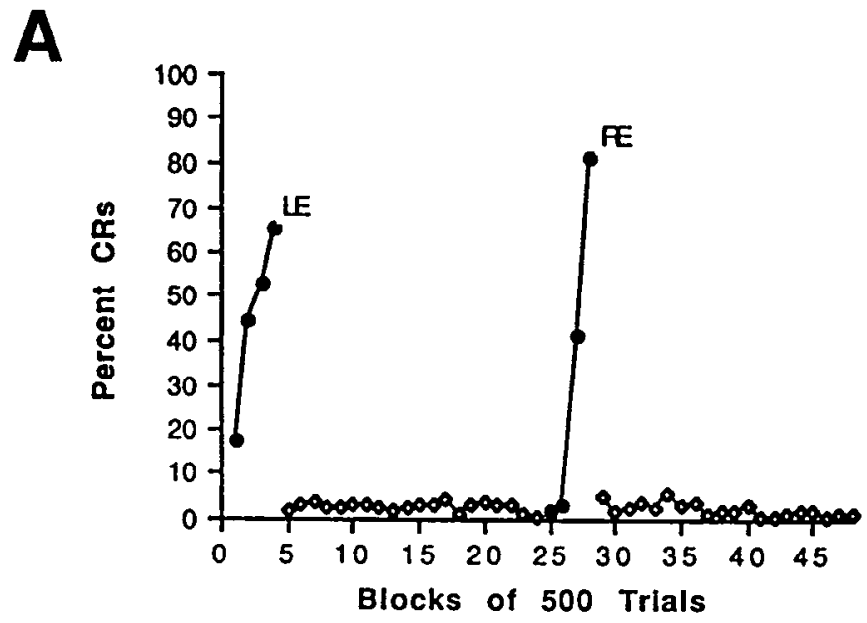

B

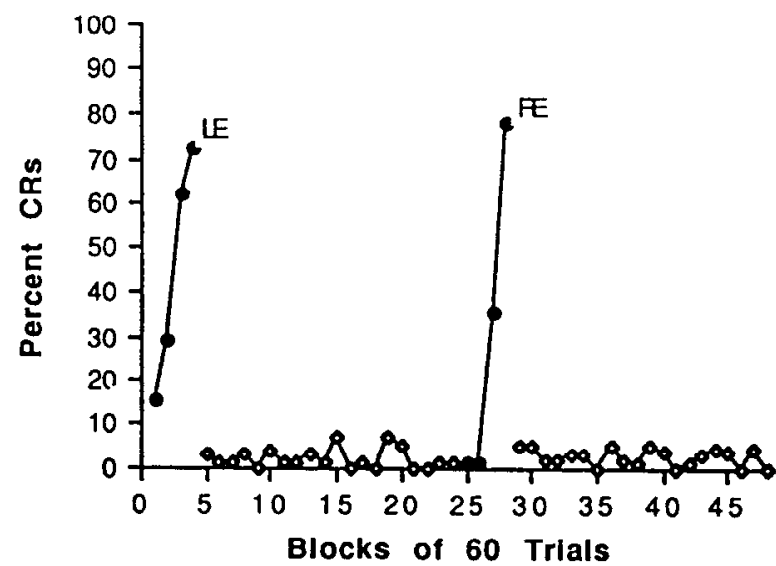

Figure 8. \%CRs recorded during paired CS-US trials $(A)$ and on CSalone test trials $(B)$ from a rabbit given extensive training after an interpositus nucleus lesion. Each data point is the average of five training sessions (500 CS-US trials or $60 \mathrm{CS}$-alone trials). The rabbit received 20 prelesion sessions on the left side and then was given a left interpositus nucleus lesion. After the lesion, the rabbit received 100 left-side training sessions, 20 right-side training sessions, and then an additional 100 left-side training sessions. $L E$, left eye; $R E$, right eye.

most of their lesions did not completely destroy the critical region of the anterior interpositus nucleus (see General Discussion).

Three other issues deserve mention. First, Welsh and Harvey did not demonstrate that the infrequent, low-amplitude, longlatency responses to the CS they reported were CRs. To do so, it is essential to run a group given comparable exposure to unpaired presentations of CS and US to control for the real possibility that the responses they reported were due to sensitization or other nonassociative processes as a result of extensive postlesion training. They did not run any control groups. This is perhaps a moot point since none of our 28 lesioned animals showed any such responses. But it is somewhat surprising that their report of residual CRs could possibly have been taken seriously in view of the fact that they did not run the group essential to control for nonassociative processes.

The second issue concerns the "adaptiveness" of the residual postlesion response they claim to have obtained. They report a mean postlesion response onset latency of $348 \mathrm{msec}$ and peak latency of $908 \mathrm{msec}$ in their "effective" group. Further, this response is only a small fraction of the normal CR amplitude ( $16 \%$ of preoperative levels). The normal $\mathrm{CR}$ is learned as a response that anticipates aversive stimulation of the eye by the US. In well-trained normal animals, it is maximal in amplitude at about the time of onset of the US (e.g., Steinmetz, 1990a). It provides maximal anticipatory protection of the eye. The tiny post-US response reported by Welsh and Harvey cannot serve this function.

The third issue concerns the permanence of the interpositus lesion abolition of the eye blink CR. Kelly et al. (1990), apparently unaware of much of our published work, argue that we do not see recovery of the eye blink CR following interpositus lesions because we "examined the effects of these lesions after only a period of days following the lesions" (p 16). As noted earlier, we have periodically trained and retrained animals with effective interpositus lesions for up to 8 months postlesion; the animals never showed any signs of CRs. In the present experiments, animals were trained postoperatively for up to $24 \mathrm{~d}$ and never showed any signs at all of CRs, even thought CR measurements were taken for a $2500 \mathrm{msec}$ time period following CS onset. One of us (J.E.S.) has trained animals with effective interpositus lesions for very long periods of time (Steinmetz and Steinmetz, 1991; Steinmetz et al., in press). An example is shown in Figure 8 of an animal that was trained preoperatively, sustained an interpositus lesion that completely abolished the CR (with no effect on the UR), and received $200 \mathrm{~d}$ of postoperative training. This animal never showed any signs of eye blink CRs postoperatively even though right eye blink training was possible.

In sum, the evidence is conclusive that complete destruction of the critical region of the interpositus nucleus completely and permanently prevents eye blink $\mathrm{CR}$ acquisition and completely and permanently abolishes the previously learned eye blink CR, regardless of the amount of pre- or postoperative training.

\section{Experiment II. Do Interpositus Lesions That Abolish the CR Alter Performance of the UR?}

Welsh and Harvey (1989a) make much of their reported finding that their "effective" interpositus lesion causes persisting changes in the UR. The actual change they report is extremely small, involving only modest changes in the percentage, peak latency, and rise time of the UR to very low intensities of US. They report no lesion effect on reflex amplitude or onset latency, even at the lowest US intensities. Furthermore, they did not determine the effect of the lesion on performance of the UR in the same animals; that is, they did not determine the effect of the lesion on the UR compared to the same UR prior to lesion. In this experiment, we evaluate the effect of interpositus lesions that completely abolish the eye blink CR on properties of the UR in the same group of animals, comparing pre- and postlesion URs. A control group of animals given the same amount of experience with stimuli but with random unpaired presentations of the stimuli is used for comparison.

\section{Materials and methods}

Subjects. The subjects for this experiment were 19 adult male New Zealand White rabbits. They were housed in a $12 \mathrm{hr}$ light $/ 12 \mathrm{hr}$ dark, temperature-controlled environment. They were cared for by the ex- 
perimenters, staff, and veterinarians of the University of Southern California.

Trained group. A total of eight animals were run. In the following protocol (summarized in Table 1), the amplitude of each rabbit's reflexive reaction to different air puff intensities was measured at six points during the course of training for classical conditioning. Each input/ output ( $\mathrm{I} / \mathrm{O})$ testing measured the amplitude, latency, amplitude-time area, and rise time of the reflexive blinks.

On the first day, the left eye of each rabbit was anesthetized with ophthalmic lidocaine and a loop of 6-0 nylon suture was placed into the temporal margin of the NM. This loop would be used in $\mathrm{I} / \mathrm{O}$ testing and in classical conditioning to attach a minitorque potentiometer for measuring movement of the membrane. The following day, each rabbit was tested for reaction to air puff. $1 / O$ test $l$ was used to assess reactions to air puff intensities with each rabbit having as little experience with the experimental condition as possible.

The protocol for each $\mathrm{I} / \mathrm{O}$ test consisted of the following. Each rabbit was placed in a standard Plexiglas restrainer and fitted with a temporary head stage that held a minitorque potentiometer (which attached to the loop of nylon suture in the membrane) and a nozzle for directing air puff to the cornea. In this and in all testing and training to follow, the external eyelids were retracted in order to prevent their interference with measurement of nictitating membrane extension. The rabbits were placed in a sound-attenuating chamber with a speaker located about $15 \mathrm{~cm}$ above and in front of the ears.

Each I/O test consisted of 10 presentations of corneal air puff ( 98 msec duration) at each of four intensities $(1,2,3$, and 4 psi). Each presentation of a stimulus was varied by an average of $30 \mathrm{sec}(20-40$ sec range). All presentations and collection of data were controlled by computer (see below). Nictitating membrane extension was intentionally calibrated on an 8 bit ADC 0808 A/D converter.

Each rabbit was then adapted for $3 \mathrm{~d}$ to the conditioning apparatus. Adaptation consisted of placing each rabbit in the restrainer and animal chamber for a period of $1 \mathrm{hr}$ without any stimulus presentations. On the next day, each rabbit was tested for reflexes to the four air puff intensities as before. This $I / O$ test 2 was used to assess the effects of adaptation on reflexive responding.

Over the following $5 \mathrm{~d}$, each rabbit was trained for classical conditioning of the nictitating membrane response. The rabbit was placed in a restrainer and inside the sound-attenuating chamber as for the $\mathrm{I} / \mathrm{O}$ tests and for adaptation. Each training session consisted of 12 blocks of trials, with 9 trials per block, for a total of 108 trials per day of training. The first trial of every block was a conditioned stimulus (CS)alone test trial. The CS was a $1 \mathrm{kHz}, 85 \mathrm{~dB}$ SPL, $348 \mathrm{msec}$ tone. The following eight trials were paired tone-air puff trials. The air puff unconditioned stimulus (US) was a $3 \mathrm{psi}\left(2.1 \mathrm{~N} / \mathrm{cm}^{2}\right), 98 \mathrm{msec}$ air puff. Tone onset preceded air puff onset by $248 \mathrm{msec}$, and both the tone and air puff stimuli coterminated.

Presentation of stimuli and collection of data were made on line by an interface (Lavond and Steinmetz, 1989a) and software (8088 machine language and FORTH) for the IBM-PC/XT and compatibles. Each trial began with a $248 \mathrm{msec}$ baseline period, followed by a $248 \mathrm{msec} \mathrm{CS}$ period (the period starting with tone onset), and ended with a $248 \mathrm{msec}$ US period (the period starting with air puff onset). The computer collected information about the position of the nictitating membrane every $2 \mathrm{msec}$ (animals $87-125,87-126,87-127$, and $87-128$ ) or $4 \mathrm{msec}$ (animals 88-004, 88-005, 88-006, and 88-008).

The computer measured amplitude, latency (onset and peak), and amplitude-time areas during the $C S$ and the US periods, and determined trials in which a conditioned response (CR) occurred and when criterion for learning was reached. A CR was any movement after CS onset that equaled or exceeded $0.5 \mathrm{~mm}$ of nictitating membrane extension. Criterion for learning consisted of the first lime that a CR occurred in 8 out of 9 consecutive trials. \%CRs was reported for each block and for the entire training session. Trials were not counted toward criterion if movement in the baseline period exceeded $0.7 \mathrm{~mm}$ or if a movement of $0.7 \mathrm{~mm}$ occurred in the CS period within $25 \mathrm{msec}$ after CS onset. Typically about $5 \%$ of trials are rejected from analysis by these criteria (e.g., Gormezano et al., 1983; Lavond et al., 1987).

The next day, each rabbit was again tested for reflexes to the four air puff intensities $(I / O$ test 3$)$. This tested for the influence of training on reflexes.

Each rabbit was given 1 additional day of training. This additional overtraining was to guard against the possibility that $\mathrm{I} / \mathrm{O}$ test 3 interfered with performance.
Table 1. Summary of trained group protocol

\begin{aligned} Day & Condition \\ \hline 0 & NM suture \\ 1 & I/O test 1 \\ 2 & Adaptation $(3 \mathrm{~d}) \\ 5 &$ I/O test 2 \\ 6 & Classical conditioning $(5 \mathrm{~d}-$ acquisition $) \\ 11 &$ I/O test 3 \\ 12 & Classical conditioning $(1 \mathrm{~d}-$ overtraining $) \\ 13 &$ Surgery - interpositus lesion \\ 14 & Recovery period $(7 \mathrm{~d}) \\ 21 &$ I/O test 4 \\ 22 & Classical conditioning $(5 \mathrm{~d}-$ retention/relearning $) \\ 27 &$ I/O test 5 \\ 28 & I/O test 6\end{aligned}

Following all training, the left interpositus nucleus of eight of the rabbits was destroyed by electrolytic lesion. Each rabbit was anesthetized with xylazine $(8 \mathrm{mg} / \mathrm{kg})$ and ketamine $(60 \mathrm{mg} / \mathrm{kg})$ and maintained on $1-2 \%$ halothane. Under aseptic conditions, the midline was incised and the dura exposed. The head was positioned in the stereotaxic plane of McBride and Klemm (1968) in which bregma is placed $1.5 \mathrm{~mm}$ dorsal to lambda. Two stainless steel insect pins (size 00), insulated with Epoxylite except for $0.5 \mathrm{~mm}$ exposed tips, were inserted deep into the cerebellum. The coordinates for the anterior electrode were AP $+1.5, \mathrm{ML}$ +5.0 , and DV $-13.5 \mathrm{~mm}$ from the bony landmark lambda (+ represents anterior, lateral, and dorsal). The coordinates for the posterior electrode were AP $+0.5, \mathrm{ML}+5.0$, and $\mathrm{DV}-14.5 \mathrm{~mm}$. The final vertical coordinate was actually determined by the distance from lambda of the posterior electrode $(-14.5 \mathrm{~mm})$, by the distance from the first recorded cerebellar cortical cells $(-7.5 \mathrm{~mm})$, by the recording of unit activity near the target location $(0 \mathrm{~mm})$, and by ascending from a recording of auditory evoked responses from the dorsal cochlear nucleus (approximately $2 \mathrm{~mm}$ ). At the targeted location $2 \mathrm{~mA}$ of anodal direct current was passed for $150 \mathrm{sec}$ through each electrode referenced to the skin. The skin was sutured and wound wiped with the antiseptic microbicide Betadine ointment. Each rabbit was monitored for postoperative recovery from anesthesia. After $7 \mathrm{~d}$ of recovery from the surgery, each rabbit was again tested for reflexes to the four intensities of air puff $(I / O$ test 4 ). This tested for the effects of the lesion before retention/relearning began.

Next began $5 \mathrm{~d}$ of retention/relearning on classical conditioning using the same protocol as before the lesion. Training occurred on the same side as the original training and therefore on the same side of the interpositus lesion. We and others have shown repeatedly that effective interpositus lesions completely abolish previously learned responses (see introductory remarks).

Finally, we tested for reflexes to the four air puff intensities on the following $2 \mathrm{~d}$. I/O test 5 tested for reflexive responses immediately following retraining. $1 / O$ test 6 on the subsequent day tested for consistency of responding.

The rabbits were overdosed with sodium pentobarbital and perfused intraaortically with saline followed by formalin. The brains were extracted and postfixed in formalin for at least 1 week. Next, the brains were embedded in a gelatin-albumin matrix and fixed with paraformaldehyde in preparation for normal histology. The brains were then frozen and sectioned at $80 \mu \mathrm{m}$. The slices were mounted onto chromealum-subbed slides and dried. The sections were then stained with cresyl violet for cell bodies and counterstained with potassium ferrocyanide (Prussian blue) for the iron deposited by the lesions. A coverslip was cemented over the section and allowed to dry. Serial reconstructions were made using light microscopy and a projected image through a photographic enlarger

Control group. A total of 11 animals were given the I/O test and unpaired stimulus presentations to determine if any changes that might occur in I/O UR amplitudes as a result of training are due to nonassociative processes. The schedule and parameters of $\mathrm{I} / \mathrm{O}$ testing and 


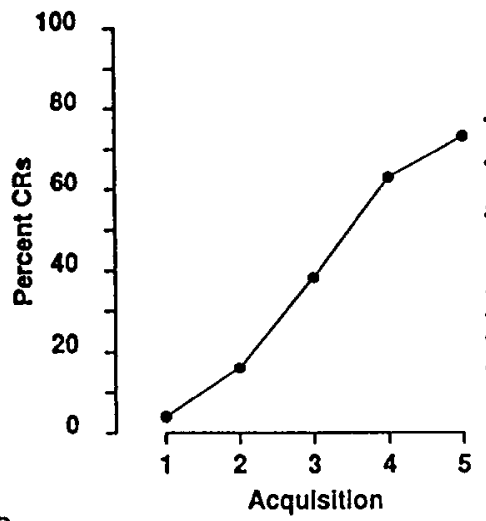

B

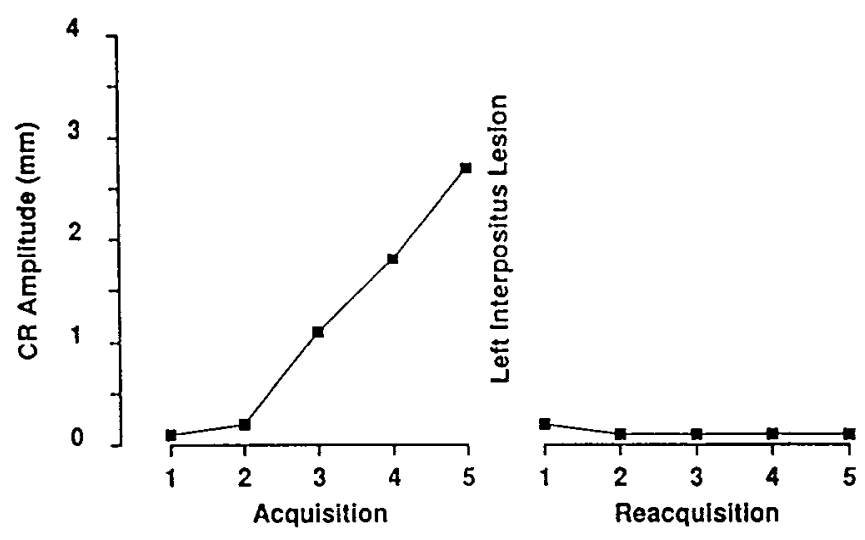

Figure 9. \%CRs $(A)$ and $\mathrm{CR}$ amplitudes $(B)$ recorded before and after left interpositus nucleus lesions in animals given paired classical conditioning training for experiment II.

training were the same as in the trained group (see above). However, rather than paired training, these animals were given $5 \mathrm{~d}$ of CS and US presentations in a pseudorandom temporal sequence. Specifically, training consisted of 204 trials (12 blocks of 17 trials) per day for $5 \mathrm{~d}$ in which each block contained eight USS-alone trials and nine CS-alone trials in the following sequence ( $t=$ tone trial, $a=$ air puff trials): $\mathrm{a}, \mathrm{t}, \mathrm{t}, \mathrm{a}, \mathrm{a}, \mathrm{t}, \mathrm{a}, \mathbf{t}, \mathrm{t}, \mathbf{a}, \mathbf{a}, \mathrm{t}, \mathrm{a}, \mathrm{t}, \mathrm{t}, \mathrm{a}, \mathrm{t}$. The intertrial interval for this group varied randomly from 1 to $33 \mathrm{sec}$ to approximate the truly random procedure suggested by Rescorla (1967).

\section{Results}

\section{Classical conditioning-paired group}

Performance on classical conditioning was analyzed with separate repeated-measures ANOVA for \%CRs, amplitude of CRs, and amplitude of URs. A two-factor within-group design compared the first $5 \mathrm{~d}$ of acquisition with the $5 \mathrm{~d}$ of retention/ relearning (before/after lesion) and each day of training (days $1-5)$. All $F$ tests reported are significant at $p<0.05$ unless stated otherwise (nonsignificant $F$ values are not reported). Only a few additional comparisons were made to keep the experiment-wise error low.

$\% C R s$. There were significant main effects before/after the lesion $\left(F_{1,7}=70.0\right)$, over days $\left(F_{4,28}=35.0\right)$, and of their interaction $\left(F_{4,28}=30.0\right)$ (Fig. $9 A$ ). The first day of acquisition was significantly different than the fifth day of acquisition $\left(F_{1,7}=\right.$ 253.0), indicating that the animals learned. The fifth day of acquisition was significantly different than the first day of retention/relearning $\left(F_{1,7}=333.0\right)$, indicating that the lesion abolished the previously learned response. The first day of acquisition did not significantly differ from any day of retention/ relearning, indicating that there was no reacquisition after the lesion with repeated training.

$C R$ amplitude. There were significant main effects before/after the lesion $\left(F_{1,7}=15.0\right)$, over days $\left(F_{4.28}-8.0\right)$, and of their interaction $\left(F_{4.28}=8.0\right)$ (Fig. $\left.9 B\right)$. The first day of acquisition was significantly different than the fifth day of acquisition $\left(F_{1,7}\right.$ $=16$ ), indicating that the animals learned. The fifth day of acquisition was not significantly different than the first day of retention/relearning, indicating that there was no reacquisition after the lesion with repeated training.

Summary. As previously reported in a number of studies, and in experiment $I$ of this article (see above), the rabbits in this experiment learned before the lesion and showed no evidencc of CRs following the interpositus lesion.

\section{Input/output UR tests-paired group}

Reflexes to 1, 2, 3, or 4 psi at various points during training (see Table 1) were analyzed by repeated-measures ANOVA for UR amplitude, amplitude-time area, frequency, rise time, and peak latency. A three-factor within-group design compared reflexes for acquisition with retention/relearning (before/after lesion), each with three test days (day) and each of these with four intensities (1-4 psi). As above, all $F$ tests reported are significant at $p<0.05$ unless stated otherwise, and only a few additional comparisons were made to keep the experiment-wise error low.

Amplitude. There was no significant main effect on reflex amplitude before/after the lesion, indicating that the size of the reflexes were the same before and after the lesion (Fig. 10A). There were significant effects of days $\left(F_{1,14}=3.9\right)$, of psi $\left(F_{3,21}\right.$ $=19$ ), and of their interaction (lesion $\times$ day, $F_{2.14}=6.4$ ), indicating that the reflexes generally changed size over days and that there were differential effects on the reflexes depending upon the lesion and day observed. No other main effects were significant. Overall, reflex amplitudes to 1 psi or 2 psi did not change, while reflex amplitudes elicited by 3 psi and 4 psi did change significantly $\left(F_{\mathrm{s}, 35}=3.4\right.$ and 3.4 , respectively). Furthermore, there were no effects at any pressure level on reflexes before versus after the lesion.

Together, these results indicate no effect of lesion on reflexive amplitudes at any psi value. However, 3 and 4 psi values did change across days. To explore this finding further, we compared I/O tests at 3 and 4 psi only. Reflexive amplitudes got significantly larger when comparing I/O tests 1 and 2 combined (pretraining) versus $\mathrm{I} / \mathrm{O}$ test 3 (posttraining) $\left(F_{1,7}=8.9\right.$ and 5.8 , respectively, for 3 and 4 psi). Paired $t$ tests were then used, showing that the 4 psi values did not change from $\mathrm{I} / \mathrm{O} 3$ to $\mathrm{I} / \mathrm{O}$ 4 , from I/O 3 to I/O 5 , and from I/O 3 to I/O 6 . That is, reflexive responding to $4 \mathrm{psi}$ remained high regardless of the lesion. On the other hand, 3 psi did significantly decrease following the lesion (I/O 3 vs. I/O $4, t_{7}=2.9$ ). However, there was no difference at 3 psi between $\mathrm{I} / \mathrm{O} 3$ and either $\mathrm{I} / \mathrm{O} 5$ or $\mathrm{I} / \mathrm{O} 6$, indicating that reflexive responses to 3 psi returned to prelesion levels after retention training.

Amplitude-time area. The main effects for amplitude-time are the same as for the amplitude data above, except that there was also a significant three-way interaction for amplitude-time $\left(F_{6.42}=2.7\right)$ (Fig. 10B). There was no significant main effect for amplitude-time before versus after the lesion, but there were significant day $\left(F_{2,14}=5.3\right)$ and pressure $\left(F_{3,21}=34\right)$ main effects and a lesion by day interaction $\left(F_{3,21}=3.5\right)$. As with amplitude data above, there were no changes in reflexive areas for 1 and 2 psi, but the reflexes for 3 and 4 psi did change $\left(F_{5.35}=3.5\right.$ and 
A

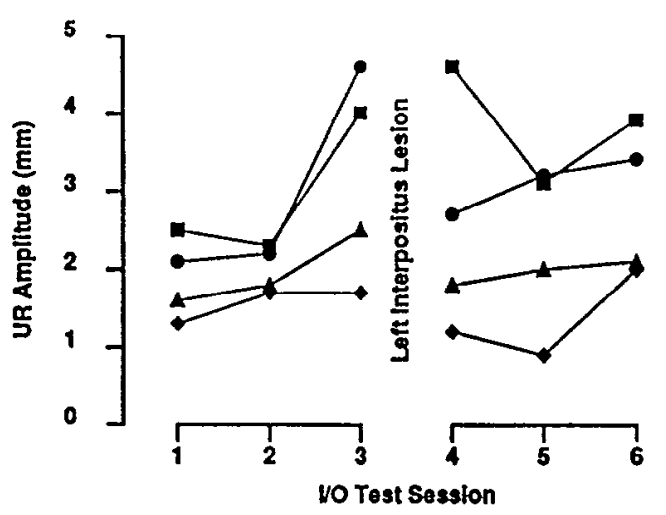

C

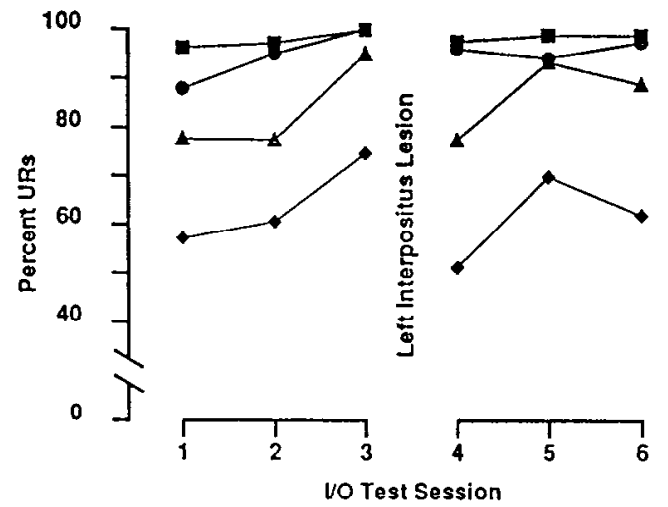

E

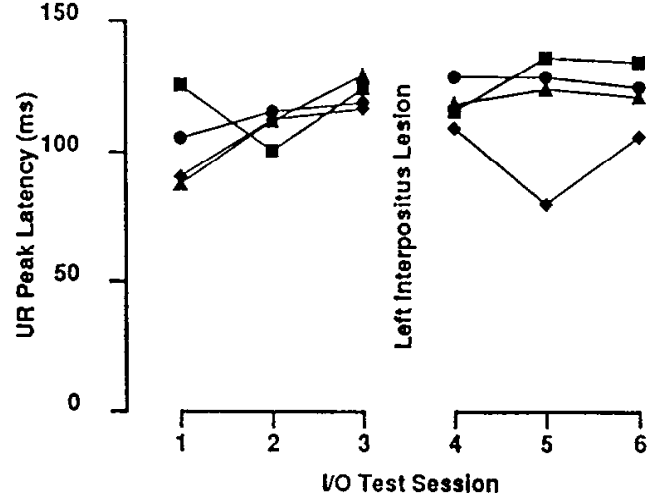

B

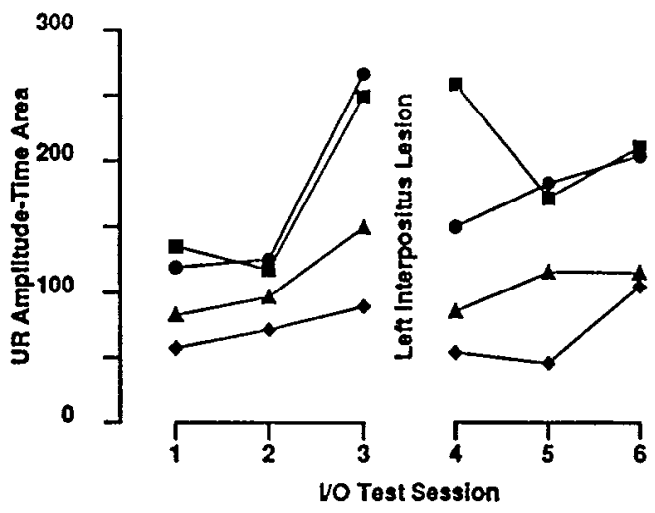

D

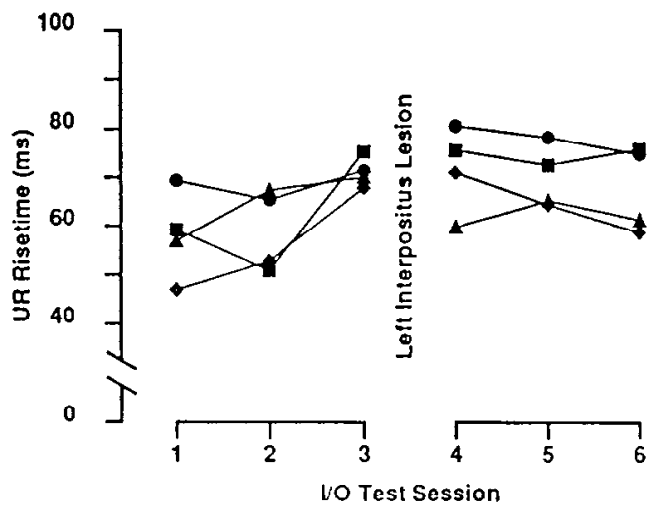

Paired Training Before Lesion

$(\mathbf{N}=\mathbf{B})$

$\longrightarrow 4 \mathrm{psi}$

$\longrightarrow 3$ psi

$\longrightarrow 2$ psi

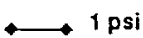

Figure 10. UR amplitudes $(A)$, UR amplitude-time areas $(B)$, \%URs $(C)$, UR rise times $(D)$, and UR peak latencies $(E)$ recorded during I/O test sessions in rabbits given paired training during experiment II. The I/O functions were established with four levels of air puff pressure.

4.5). Both psi 3 and 4 areas increased from $\mathrm{I} / \mathrm{O}$ tests 1 and 2 combined to $\mathrm{I} / \mathrm{O}$ test $3\left(F_{1,7}=8.7\right.$ and 9.7 , respectively). Paired $t$ tests were then used, showing no change at $4 \mathrm{psi}$ from $\mathrm{I} / \mathrm{O} 3$ to $\mathrm{I} / \mathrm{O} 4$, from $\mathrm{I} / \mathrm{O} 3$ to $\mathrm{I} / \mathrm{O} 5$, and $\mathrm{I} / \mathrm{O} 3$ to $\mathrm{I} / \mathrm{O} 6$. On the other hand, at $3 \mathrm{psi}, \mathrm{I} / \mathrm{O} 3$ differed from I/O $4\left(t_{7}=3.2\right)$ and from $\mathrm{I} / \mathrm{O} 5\left(t_{7}=2.5\right)$ but not from $\mathrm{I} / \mathrm{O} 6$. These results are very similar to the analysis of amplitude data above.

UR frequency. There were no significant main effects before versus after the lesion or over days, but there was a significant pressure effect $\left(F_{3,21}=17.0\right)$ (Fig. 10C). No interactions were significant. There was a significant difference between 1 and 2 psi $\left(F_{1,3}=34\right)$ and between 2 and 3 psi $\left(F_{1,7}=5.6\right)$, but not between 3 and 4 psi. Thesc results indicatc that therc were fewer URs with decreasing psi intensity, but that there were no lesion effects on percentage of URs.
UR rise time. Welsh and Harvey (1989a) used an unusual method of scoring UR onset in their rise time analysis: they measured backward from the $0.5 \mathrm{~mm}$ UR amplitude to an amplitude of $60 \mu \mathrm{m}$ and defined this as UR onset. We analyzed our rise time data using a comparable procedure, measuring backward from the $0.5 \mathrm{~mm}$ UR criterion to an amplitude of $100 \mu \mathrm{m}$ and defining this as the UR onset. An amplitude of 100 $\mu \mathrm{m}$ was chosen because it was the finest resolution possible in the recording system we used (i.e., our computer system recorded in increments of $100 \mu \mathrm{m}$ ). The rise time was then calculated as the difference between peak latency and onset latency. ANOVA indicated no significant effects, although pressure level approached significance $\left(F_{3,21}=3,0\right.$, NS) (Fig. $\left.10 D\right)$. Neverthcless, we performed limited comparisons. There was no significant difference at 3 psi comparing both I/O tests 1 and 2 com- 
A

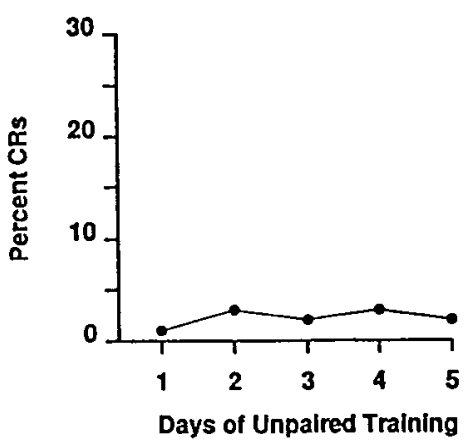

B

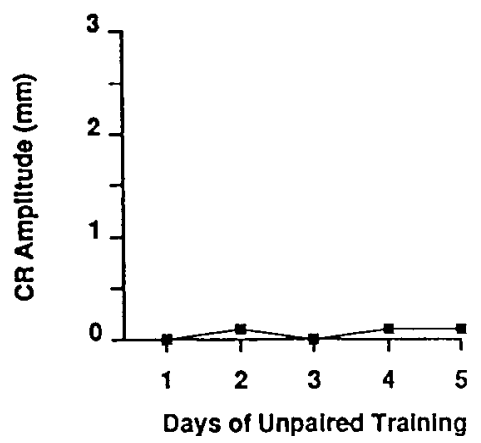

Figure $11 . \% \mathrm{CRs}(A)$ and $\mathrm{CR}$ amplitudes $(B)$ recorded during unpaired training sessions given during experiment II. Also shown are UR amplitudes for four US intensity levels that were recorded during $\mathrm{I} / \mathrm{O}$ test sessions presented to the unpaired group $(C)$. c

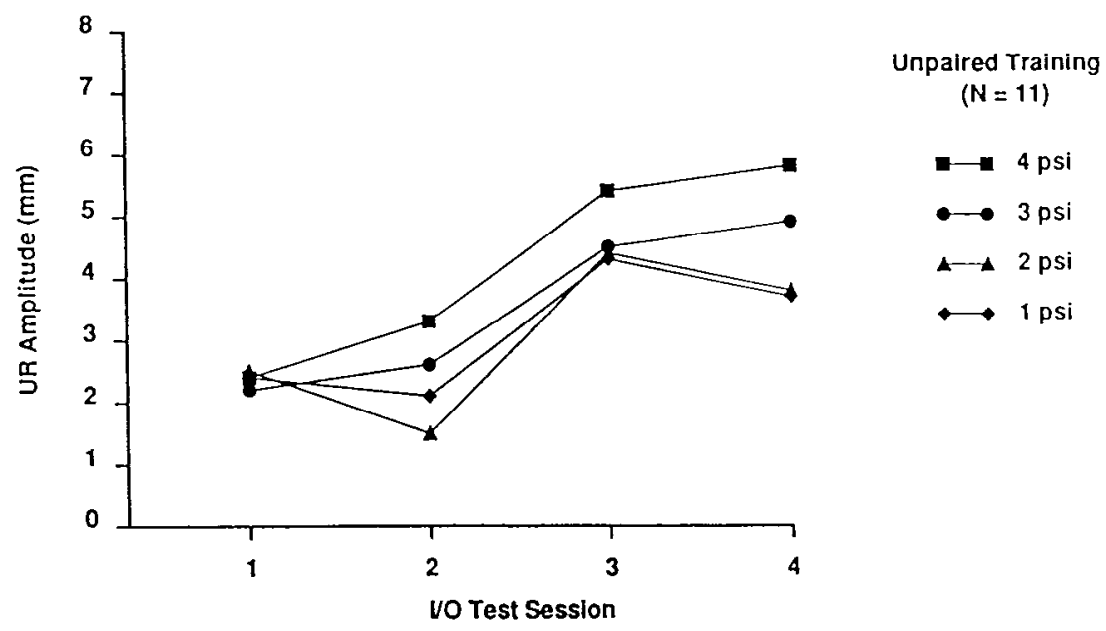

bined with $\mathrm{I} / \mathrm{O}$ test 3 . At $4 \mathrm{psi}$, there was a significant difference comparing both $\mathrm{I} / \mathrm{O}$ tests 1 and 2 combined with $\mathrm{I} / \mathrm{O}$ test $3\left(F_{1.2}\right.$ $=7.7)$. In general, there was no effect on rise time of the unconditioned reflexes to the differing psi intensities, and there was no lesion effect.

UR peak latency. There were no significant main effects for before versus after the lesion, over days, or of psi (Fig. 10E). None of the interactions were significant.

Summary. The amplitudes and amplitude-time areas of unconditioned reflexes to $1,2,3$, and 4 psi before any training were small. The reflexes to 1 and 2 psi did not change throughout all I/O tests. After training, reflexes to 3 and 4 psi were larger than before training. We think it may be significant that the intensity used for training was 3 psi. After the lesion, there was a significant reduction in the reflexes to 3 psi (I/O tcst 3 vs. 4) before training resumed. However, the responses to 3 psi returned to prelesion levels (I/O test 3 ) by the end of retention/ relearning (I/O test 6$)$.

\section{Unpaired training-control group}

Performance on classical conditioning was analyzed with separate repeated measures ANOVA for \%CRs and amplitude of CRs.

$\% C R s$. The mean \%CRs to tone alone presentations averaged over the $5 \mathrm{~d}$ of pseudorandom stimulation was 2.4 (Fig. 11A). There is no significant change in mean percent CRs over $5 \mathrm{~d}$ of training.

$C R$ amplitude. The mean amplitude of CRs to tone alone trials averaged over the $5 \mathrm{~d}$ of pseudorandom stimulation was $0.06 \mathrm{~mm}$ (Fig. $11 \mathrm{~B}$ ). There is no significant change in this measure over the $5 \mathrm{~d}$ of training.

Summary. This analysis demonstrates that the rabbits did not exhibit any signs of learning with random tone and air puff trials.

\section{Input/output tests-control group}

Reflexes to 1, 2, 3, or 4 psi at various points of training (I/O 1 , adaptation; I/O 2, random trials; I/O 3 and $\mathrm{I} / \mathrm{O} 4$ were analyzed by repeatcd mcasures ANOVA for UR amplitude; Fig. 11C). A two-factor within-group design compared reflexes over 4 test days (day) and each of these with four intensities (1-4 psi). As above, all $F$ tests reported are significant at $p<0.05$ unless stated otherwise, and only a few additional comparisons were made to keep the experiment-wise error low.

There were significant main effects for day $\left(F_{3.30}=4.3\right)$ and for pressure $\left(F_{3,30}=4.9\right)$ but not for their interaction. Individual tests followed. There was no change in reflexes for $1 \mathrm{psi}$ but there were significant increases in the reflexes for 2,3 , and $4 \mathrm{psi}$ $\left(F_{3.30}=4.1,3.5\right.$, and 3.6, respectively). The I/O 1 results were not different from $\mathrm{I} / \mathrm{O} 2$ and $\mathrm{I} / \mathrm{O} 3$ was not different from $\mathrm{I} / \mathrm{O}$ 4. There was a significant difference between I/O 1 (before adaptation) and I/O 2 (after adaptation) combined versus I/O 3 (after random pairings, $F_{1.10}=6.8$ ), indicating that reflexes over all intensities increased as a function of random exposure to the training stimuli.

In summary, these results indicate that the size of the unconditioned reflex is not an unvarying parameter. Reflex amplitudes 


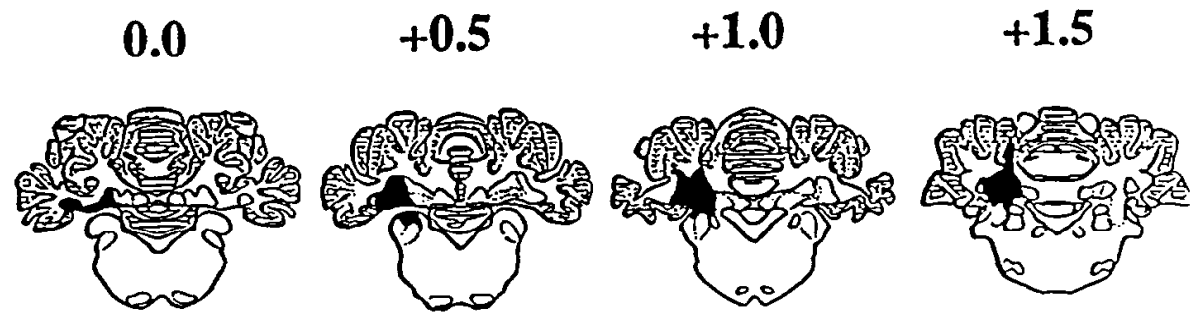

Figure 12. Largest (upper row) and smallest (lower row) extent of the lesions for rabbits given paired training before and after an interpositus lesion.
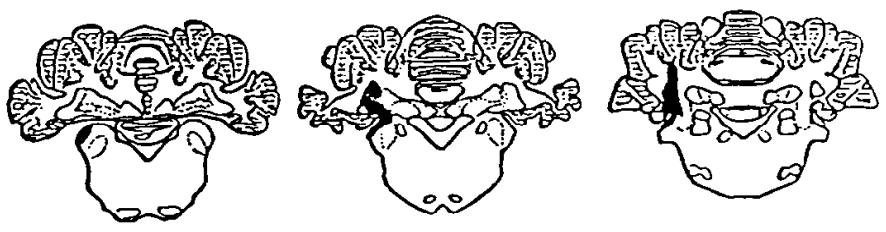
The electrolytic lesions include the anterior and middle extent of the interpositus nucleus as well as damage to the efferent superior cerebellar peduncle. In addition, there is some damage to the dorsal cochlear nucleus below the cerebellum. The schematic drawings follow those depicted in Figure 7.

increase over days of training whether the animals are given random unpaired tones and air puffs, or given paired training, as reported above.

\section{Histology}

Figure 12 shows reconstructions of the largest and smallest lesions for these eight experimental animals (see note 1). All rabbits have damage to the anterior two-thirds of the deep nuclei, encompassing the lateral border of the interpositus and the medial border of the dentate. The lateral extent of the lesions included most of the dentate nucleus in all but two animals (126 and 128), and the medial extent included all or most of the interpositus. The lesions therefore include the beginnings of the superior cerebellar peduncle, which originates in the hilus of the dentate nucleus and divides the interpositus into dorsal and ventral halves. The critical region of the interpositus, the dorsal aspect of the anterolateral interpositus, is destroyed in all animals. In addition, at least three $(005,006$, and 126$)$ and possibly four (005) rabbits have complete interpositus damage in the anterior-posterior plane. The electrode track made some incomplete cortical damage to anterior cerebellar lobules (anterior to Larsell's lobule HVI). HVI is largely damaged in two rabbits (125 and 128) with some damage in two others (004 and 126) but not damaged in the remaining three rabbits $(005,006$, and 127). In summary, the electrolytic lesions have destroyed the part of the interpositus nucleus that we have previously identified as critical for classical conditioning in all eight animals (see General Discussion).

\section{Experiment II discussion}

These experiments demonstrate no persisting effects of the interpositus lesion (that abolished the CR) on the UR in paired training or in I/O tests to US-alone presentations at four different US intensities (1, 2, 3, $4 \mathrm{psi})$ on any measure of UR performance: amplitude, amplitude-time area, frequency, latency, or rise time. The lowest intensity we used was 1 psi (which equals $0.07 \mathrm{~kg}$ / $\mathrm{cm}^{2}, 0.73 \mathrm{~N} / \mathrm{cm}^{2}$, and $7.3 \mathrm{kPa} / \mathrm{cm}^{2}$ ). We did find, however, a transient decrease in the mean UR amplitude and amplitudetime area (but not latency, frequency, or rise time) to the training intensity US ( 3 psi) immediately following lesion, but this decrease quickly recovered to prelesion levels.

In comparing our results to those of Welsh and Harvey, it is important to emphasize that they did not in fact measure the effects of interpositus lesions on reflex responses. Instead, all their analyses were done after lesion by separating the lesion animals, post hoc, into different groups. Not all animals from the initial lesion groups were used in this experiment; they do not state their selection criteria. It is worth emphasizing that Welsh and Harvey find no effect of interpositus lesion on any property of the reflex response to US alone test at US intensities at or well below the intensity used in training; indeed, they report no effect on UR amplitude at any US intensity used. As noted, the only differences they find between their lesion groups are small changes in frequency, peak latency, and rise time of the UR at low US intensities when onset latency is measured backward from the $0.5 \mathrm{~mm}$ response criterion to a $60 \mu \mathrm{m}$ amplitude. We analyzed our data in the same way and found no such effect of interpositus lesion, even at the lowest US intensity we used.

In contrast to Welsh and Harvey, we measured the effects of interpositus lesions on URs in the same animals before and after lesion. Because many factors can influence the UR and because of substantial individual differences in URs, it is essential to compare URs in the same animals before and after lesion. Their interpositus lesions often included varying amounts of cerebellar cortex (Welsh, 1987). There is now evidence that lesions of the cerebellar cortex that markedly impair or abolish the eye blink CR may cause a significant increase in the amplitude of the UR in the same animals (Logan, 1991). It is thus very possible that the differences Welsh and Harvey report between their postlesion groups are due to relative changes in their "ineffective" lesion groups, due in turn to cerebellar cortical damage in the absence of damage to the critical region of the interpositus nucleus.

In our lesion group in this experiment, both amplitude and amplitude-time area UR measures showed a significant but very transient decrcasc immediatcly following lesion, with complete recovery to preoperative levels, in the I/O UR data for the training US intensity ( 3 psi). However, latency, frequency, and rise time measures did not show this effect; that is, they were not sensitive measures. It is likely that the amplitude-time area measure is the most accurate reflection of the amount of activity in the motor nuclei. We showed some time ago that this measure of the NM response is very highly correlated with neuronal activity in motor nuclei (Cegavske et al., 1979). Amplitude is of course highly correlated with amplitude-time area. 
Welsh and Harvey present no evidence that UR rise time and latency are the most valid or useful measures of "performance." The US intensity is the most powerful determinant of the UR, yet their data suggest that UR frequency, peak latency, and rise time do not even vary with US intensity except at the lowest intensities. ${ }^{2}$ On the other hand, their data suggest that UR amplitude does vary systematically with US intensity. Importantly, as noted, they report no differences between "effective" and "ineffective" lesion groups in UR amplitude as a function of US intensity. Our results indicate that UR rise time and latency do not vary systematically or significantly with air pressure, in marked contrast to amplitude and amplitude-time area measures, which increase in a highly significant manner with increasing air pressure (see Figs. 10,11). This argues that UR rise time and latency are not the most useful measures of behavioral performance in this behavioral learning paradigm. We did find that UR frequency increased significantly with US intensity. However, the interpositus lesion effective in abolishing the CR had no effect on UR frequency at any US intensity.

A striking and somewhat unexpected finding in the present experiment is the marked overall increase in UR amplitude over US alone $\mathrm{I} / \mathrm{O}$ tests that resulted from experience (Figs. 10, 11). This increase does not appear to be associative in nature; the same overall increase occurs before and after training in the control group given pseudorandom unpaired training. Further, the interpositus lesion that abolishes the CR has no effect on this experience-dependent increase in UR amplitude. This finding indicates that the UR itself is "plastic" and can change as a result of experience with the situation and stimuli, independent of increases in associative strength of the CR. There is a literature indicating that adaptation of the eye blink reflex occurs. Specifically, in both rabbits and humans, increased or decreased loading of the external eyelid can increase or decrease the gain of the reflex and this gain persists immediately following removal of the load (Evinger and Manning, 1988). Further, the reflex can be modulated by presentations of "neutral" stimuli prior to learning, the phenomenon of reflex facilitation (e.g., Wcisz and LoTurco, 1988). The important point of these observations here, and our results, is that the amplitude and other properties of the eye blink UR can change considerably quite independently of the development of conditioned eye blink responses to a CS. The key findings in this experiment are (1) interpositus lesions that abolish the eye blink CR have no persisting effects on any property of the UR to US-alone tests, even at low intensities, and (2) experience in the situation results in a marked increase in UR amplitudes to US-alone tests, independent of the development of CRs.

\footnotetext{
${ }^{2}$ In order to maximize the sensitivity of UR measurement, we completed reflex testing and training on two separate groups of animals, using intensities of 0.13 psi (which equals $0.009 \mathrm{~kg} / \mathrm{cm}^{2}, 0.09 \mathrm{~N} / \mathrm{cm}^{2}$ and $0.9 \mathrm{kPa} / \mathrm{cm}^{2}$ ) or $0.50 \mathrm{psi}$ (which equals $0.035 \mathrm{~kg} / \mathrm{cm}^{2}, 0.35 \mathrm{~N} / \mathrm{cm}^{2}$ and $3.5 \mathrm{kPa} / \mathrm{cm}^{2}$ ). Animals were given reflex tests to the US alone at the US intensity used for training. None of the four animals trained at 0.13 psi exhibited CRs; that is, they did not learn. Four of seven animals trained at 0.50 psi developed CRs, and three animals exhibited no CRs. Thus, the two lowest US intensities used by Welsh and Harvey are below threshold for learning; they do not sufficiently activate the necessary US pathways. Consequently, reflex testing at these intensities is not relevant to the issue of CR versus UR performance. It appears that 0.5 psi is approximately at threshold (four of seven animals learned). Interestingly, in the four animals that learned, the CR amplitude (mean $=2.3 \mathrm{~mm}$ ) was considerably larger than the UR amplitude (mean $=1.4 \mathrm{~mm}$ ). Interpositus lesions made in these four animals completely abolished the CR $[t(3)=8.49 ; p<0.01]$ and had no significant effect on the UR $[t(3)=1.35$; NS $]$. Thus, even at the lowest US intensity that supports learning, where UR amplitude is well below CR amplitude, the interpositus lesion completely abolishes the CR and has no effect on the UR.
}

\section{Experiment III. Do Lesions of Eye Blink Motoneurons Impair Equally the CR and the UR?}

Welsh and Harvey (1989a) argue that abolition of the eye blink CR following interpositus lesion is merely a "performance" effect-that the lesion alters the properties of the UR and this will have disproportionate effects on the CR because the $C R$ is somehow more "fragile" than the UR. Welsh and Harvey do not define "performance" other than in terms of the properties of the UR. The experiment reported here was designed to test their assertion that procedures that alter performance of the UR will have disproportionate effects on the CR.

In an important series of studies, Disterhoft et al. (1985) made lesions of the accessory abducens nucleus in rabbits previously trained in eye blink conditioning (they used a white noise CS and corneal air puff US, and measured NM extension). Results were striking: there were significant reductions in amplitudes of the CR and the UR immediately after lesion. However, in all cases they report varying degrees of recovery of the $C R$ and the UR. Indeed, in the one example shown (their Fig. 5, p 947), the $\mathrm{CR}$ recovered to a greater extent than the UR. If anything, the $\mathrm{CR}$ appeared to be less fragile, less influenced by variables that act on performance, than the UR itself. Because this finding has fundamentally important implications for the "performance" argument, we replicate and extend these observations here using both measures of URs to US-alone trials and CRs to paired CSUS trials and CS-alone trials.

\section{Materials and methods}

Training schedule. Results are reported for nine animals. All animals were trained and tested using the same general schedule as in experiment II, with simplification. Animals were habituated to the apparatus for 2 d. On day 3 they were given the $\mathrm{I} / \mathrm{O}$ tests at $1,2,3$, and 4 psi, using the same procedure as in experiment II. They were then trained for 5 $\mathrm{d}$ using the standard conditioning procedure exactly as in experiment II. They were then given another day of $\mathrm{I} / \mathrm{O}$ test. Lesions were then made, and the following day the animals given a day of $\mathrm{I} / \mathrm{O}$ testing to the US and then trained for $5 \mathrm{~d}$, given an I/O test day, and additional training and testing sessions.

Accessory abducens lesions. Animals were anesthetized with halothane. The lesion electrode (00 insulated insect pin, $150-200 \mu \mathrm{m} \mathrm{ex}-$ posed tip) was lowered into the vicinity of the accessory abducens nucleus ipsilateral to the trained eye and stimulus trains given $(100 \mathrm{msec}$ train duration, $0.1 \mathrm{msec}$ pulse duration, $10-15 \mu \mathrm{A}, 400 \mathrm{~Hz}$, cathodal stimulation), and the electrode positioned so that the threshold response to stimulation was "pure" eyeball retraction and NM extension. We used the coordinates for the accessory abducens nucleus reported by Gray et al. (1981): AP obtained from regression equation $X=0.69 y+$ $1.0 \mathrm{~mm}$, where $y=$ distance between lambda and bregma; $\mathrm{ML}=2 \mathrm{~mm}$ from midline; $\mathrm{DV}=20.9 \mathrm{~mm}$ ventral to bregma (however, our best DV was 1-1.5 mm lower than this value). The lesion current was $1 \mathrm{~mA}$ for $30-45 \mathrm{sec}$. Following $1 \mathrm{~d}$ of recovery, animals were given the $\mathrm{I} / \mathrm{O}$ tests and training as indicated above. Three sham lesion animals were also done, using the same schedule and same duration of anesthesia as the lesion animals, to control for possible long-lasting effects of the anesthetic, and so on. In addition, three animals sustained lesions dorsal to the region of the accessory abducens nucleus and thus served as lesioned controls.

\section{Results}

Figure 13 shows results for three animals, all of whom sustained very large lesions in the region of the accessory abducens nucleus ipsilateral to the trained eye, plotting mean amplitude (as percentage of prelesion amplitude) of the UR to US-alone stimuli of the training intensity ( 3 psi) and mean amplitude (as percentage of prelesion amplitude) of the CR to CS-US and CSalone trials at successive 5-6 d periods over the course of post- 
operative training and testing. The mean prelesion amplitudes were $\mathrm{UR}=13.3 \mathrm{~mm}, \mathrm{CR}=6.7 \mathrm{~mm}$. Note that the mean amplitude of the UR to US-alone stimulation at the end of preoperative training was twice as large as the mean CR amplitude. Following destruction of the accessory abducens nucleus, both the UR and the CR were virtually abolished. However, over the course of postoperative training and testing, the CR amplitude showed pronounced recovery whereas the UR shows relatively little recovery. These data were analyzed with a $2 \times$ 4 between-groups mixed ANOVA. Response type (UR vs. CR) was not significant; session was highly significant $\left(F_{3,12}=17.9\right.$; $p<0.001)$, and the interaction was significant $\left(F_{3,12}=4.2 ; p<\right.$ $0.05)$. Planned comparisons indicated no signiticant change in the \%UR measure over postoperative sessions but a significant increase in the \%CR measure over postoperative sessions $\left(F_{1,2}\right.$ $=50.74 ; p<0.05$ ). In short, the CR amplitude recovered significantly over the postoperative training sessions but the UR did not exhibit significant recovery over postoperative training sessions.

The sham lesion animals showed no changes in either CR or UR amplitudes when tested at the same time after anesthesia as the lesion animals. Further, a group of three animals served as lesion controls; in these animals the lesion caused little or no damage to the accessory abducens nucleus. These animals showed no decrement in CR or UR performance following lesion. The effective accessory abducens lesions and the control lesions are reconstructed in Figure 14. The largest effective lesion completely destroyed the accessory abducens and invaded regions surrounding the nucleus. The smallest lesion invaded a portion of the accessory abducens and included some adjacent tissue. The animal with the most profound behavioral effect (91-058) was continued for an additional $10 \mathrm{~d}$ of training and testing. The UR to US-alone showed no further recovery beyond that seen at $15 \mathrm{~d}$, but the CR amplitude showed further recovery. Subsequent histological analysis showed that this rabbit had the largest lesion.

In sum, lesions of the accessory abducens nucleus that massively and permanently impair performance of the UR (recovery not statistically significant and to only $23 \%$ of prelesion amplitude) result in much less impairment of the CR (recovery statistically significant and to $56 \%$ of prelesion amplitudes), even though the UR amplitude was substantially higher than the CR amplitude before lesion. This finding replicates and extends the earlier report by Disterhoft et al. (1985) and demonstrates clearly that direct and substantial impairment in performance of the behavioral response, as measured by the UR amplitude in response to US-alone stimuli, causes much less impairment in the CR amplitude in response to the CS.

\section{Experiment III discussion}

The result of this experiment shows clearly that massive and permanent impairment of the animal's ability to perform the UR following lesion of the accessory abducens nucleus has relatively little persisting effect on the ability of the animal to perform the CR. This stands in marked contrast to the effect of the interpositus lesions in the present experiments, which caused complete and permanent abolition of the CR but had no effects on the UR. Welsh and Harvey define "performance" as performance of the UR and argue that very small effects of lesions on the UR will cause vastly greater effects on the CR. The present result shows this argument to be wrong and the facts to be just the opposite. Although the UR exhibits some plasticity follow-

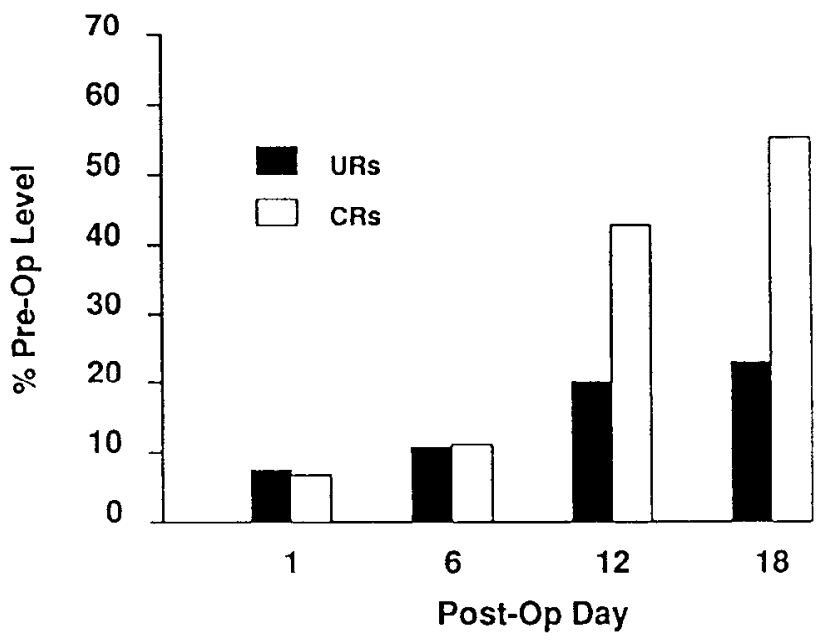

Figure 13. UR amplitudes (solid bars) and CR amplitudes (open bars) recorded 1, 6, 12, and $18 \mathrm{~d}$ after abducens lesions were given. The amplitudes are expressed as percentages of presurgery levels.

ing lesion impairment, the CR exhibits much greater plasticity in recovery following lesion impairment of the UR than does the UR itself.

\section{General Discussion}

\section{Effects of interpositus lesions on the CR}

Results of experiments I and II demonstrate conclusively that appropriate electrolytic lesions of the anterior interpositus nucleus completely and permanently prevent acquisition and completely and permanently abolish retention of the conditioned eye blink response. This result confirms and extends results from a number of earlier studies reporting the same finding (e.g., McCormick and Thompson, 1984a; Lavond et al., 1985; Yeo et al., 1985a). Such completely effective lesions have now been reported in well over 100 rabbits. In initial electrolytic interpositus lesion studies, we found that if the lesion did not completely destroy the critical region of the interpositus, a residual CR remained; this CR had a lower amplitude, a lower frequency of occurrence, and an increased onset latency (Clark et al., 1984). As noted earlier, Welsh and Harvey (1989a) reported a group of "effective" interpositus electrolytic lesion animals, 4 of whom never showed any signs of residual CRs throughout postoperative training, and 11 of whom did have significant residual CRs postlesion; that is, the lesions were not completely "effective" in these 11 animals. In short, they merely succeeded in replicating both our earlier complete and incomplete lesion results.

There are several issues of relevance to these interpositus lesion results, some of which were raised by Welsh and Harvey and others as critiques of our earlier work; we address these issues here.

1. Period of measurement on CS-alone test trials. It has been argued that we did not record the CR for a sufficient time postCS onset on CS-alone test trials to record "late" CRs, for example, Welsh and Harvey's (1989a) reported response with an onset latency of about $300 \mathrm{msec}$. Actually, although not reported, in our initial cerebellar lesion studies we recorded the NM extension response on a polygraph for a $1000 \mathrm{msec}$ period post-CS onset (e.g., McCormick and Thompson, 1984a), and in subsequent studies we always recorded for at least $500 \mathrm{msec}$ post-CS onset on CS-alone trials. In the present experiments, we recorded the CR on CS-alone trials for $2500 \mathrm{msec}$. 


\section{Lesion Group}
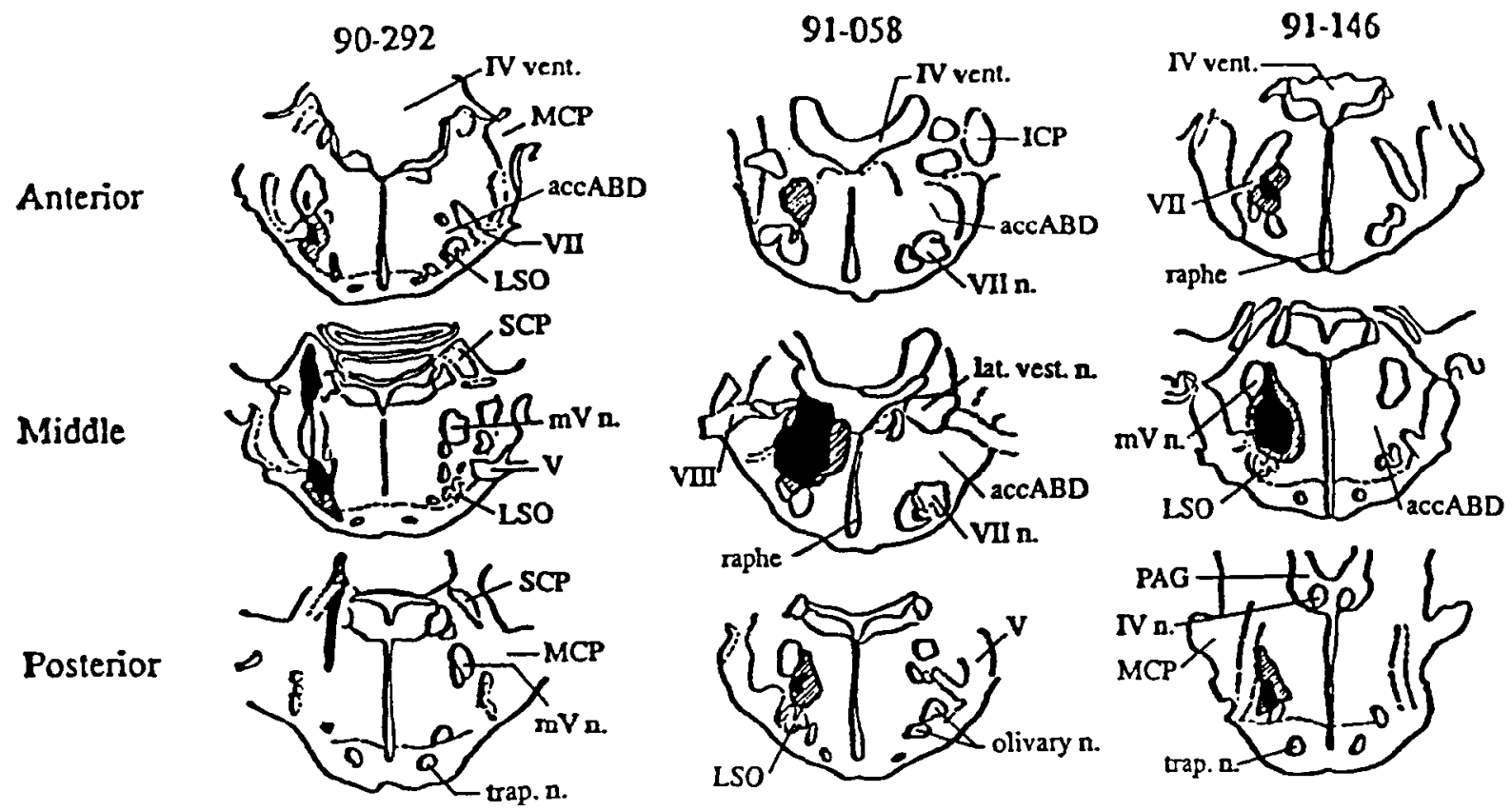

\section{Control Group}

$90-282$
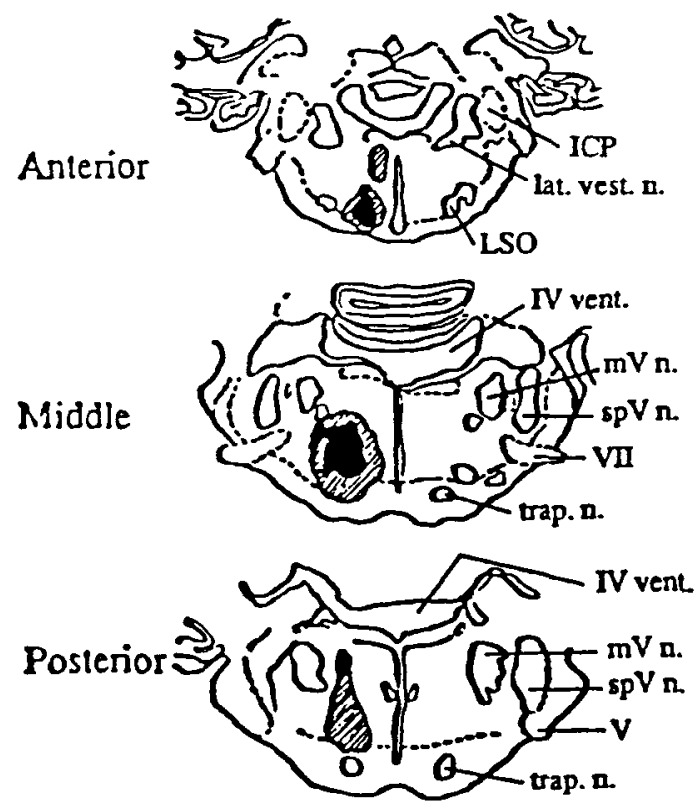
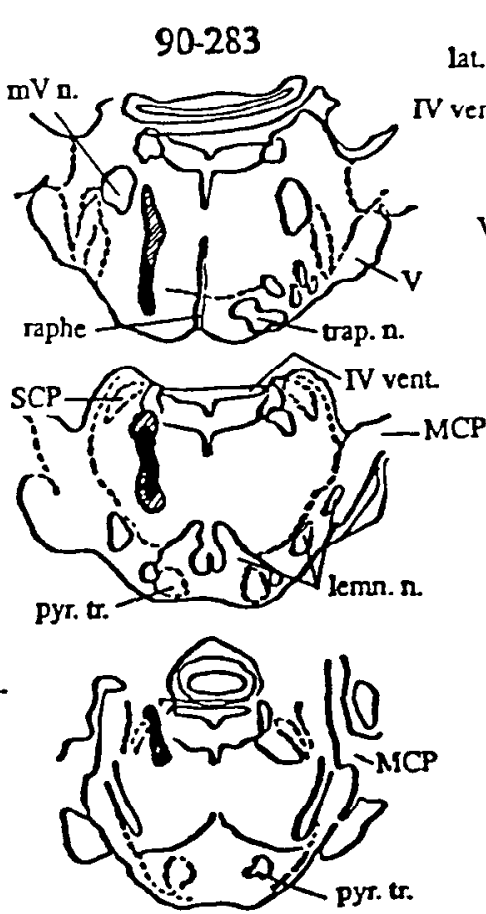
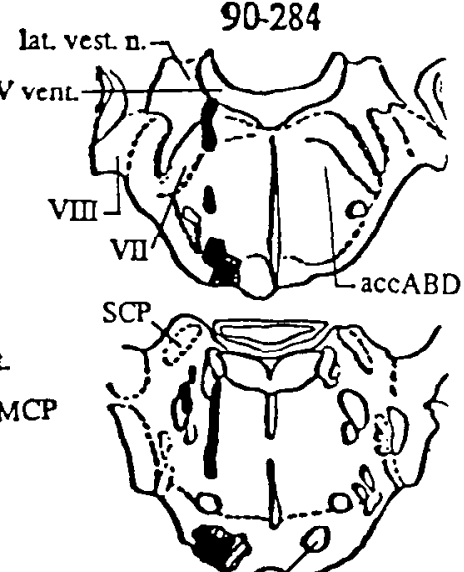

trap. n.

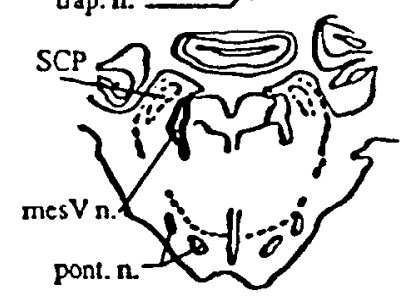

Figure 14. Coronal brain sections showing the extent of the lesion in the vicinity of the accessory abducens nucleus for the lesion and control groups. $I V$ vent, fourth ventricle; $S C P$, superior cerebellar peduncle; $M C P$, middle cerebellar peduncle; $I C P$, inferior ccrcbellar peduncle; $a c c A B D$, accessory abducens nucleus; VIII, eighth cranial nerve; $V I I$, seventh cranial nerve; $V I I n$, nucleus of the seventh cranial nerve; $m V n$, motor nucleus of the fifth cranial nerve (Vth); $s p V n$., spinal nucleus of the Vth: mes $V n$., mesencephalic nucleus of the Vth; $V$, fifth cranial nerve; $I V n$., nucleus of the fourth cranial nerve; trap. $n$., trapczoid nucleus; $L S O$, lateral superior olive; olivary $n$., olivary nuclei; lat. vest. $n$., lateral vestibular nucleus; $P A G$, periaqueductal gray; lemn. n., lemniscal nuclei; pyr. tr., pyramidal tract; pont. $n$., pontine nuclei.

2. Use of the $0.5 \mathrm{~mm} N \mathrm{NM}$ extension criterion standard in the field. Welsh and Harvey argue that this criterion is not sufficiently sensitive to detect small CRs, particularly for onset latency measurement, and they measured backward from $0.5 \mathrm{~mm}$ to a $60 \mu \mathrm{m}$ movement. The fact that Welsh and Harvey's onset latency distributions on CS-alone test trials in their "effective" lesion animals were not randomly distributed in time is of course because 11 of their animals did not have completely effective 
lesions; that is, they still showed CRs. All of the effectively lesioned animals in the present experiments showed only spontaneous responses with onset latencies distributed randomly over the CS-alone test trial periods, even when we used the 100 $\mu \mathrm{m}$ response amplitude measurement. Indeed, these spontaneous responses were at or below the rates obtained in earlier studies for control animals not given paired training.

Lavond et al. (1990a) recently reported an extensive study in which animals were trained for $10 \mathrm{~d}$, given interpositus lesions, and then retrained for at least $20 \mathrm{~d}$ (one animal for $26 \mathrm{~d}$ ), measuring both NM extension and orbicularis oculi EMG. Preoperatively, the EMG measure had a significantly lower threshold and significantly shortcr latency and showed a much greatcr degree of increase over training than did NM extension-it is a significantly more sensitive measure than NM extension. The lesions completely and permanently abolished both measures of the CR.

3. Amount of postoperative training. It has been argued that the interpositus lesion abolition of the $\mathrm{CR}$ is temporary and that we have not given sufficient postoperative training to see recovery (e.g., Kelly et al., 1990). Actually, Welsh and Harvey reported no significant increase in the CRs over postoperative training in their "impaired" lesion group. This lack of recovery from clearly incomplete lesions confirms our earlier report that the attenuated CR does not recover following lesions that were not completely effective (Clark et al., 1984). This result argues strongly that the interpositus lesion destroys the memory trace itself or the essential efferent pathway from the memory trace. Partial damage to systems afferent to memory traccs that impairs learned responses, for example, sensory pathways, is characteristically followed by full recovery of learned response with subsequent training in a variety of learning situations (for reviews, see Lavond et al., 1984b; Finger et al., 1988). As noted, we earlier reported that periodic training and retraining of animals for up to 8 months following effective interpositus lesion yields no signs of CRs (Lavond et al., 1984b). Animals trained with the conditions we use require only $2-3 \mathrm{~d}$ of training to reach learning criterion. In the present studies, animals were given $24 \mathrm{~d}$ of postoperative training and no CRs developed. Lavond et al. (1990a) trained animals for $20 \mathrm{~d}$ postoperatively with no CRs. In both Lavond's study and group P10 in the present study, animals were given $10 \mathrm{~d}$ of preoperative training prior to lesions. Finally, Steinmetz et al. (1991, in press) have now retrained animals for $200 \mathrm{~d}$ postlesion (they were trained prelesion) with no signs of CRs. There is never any recovery at all of the CR following appropriate lesion of the interpositus nucleus.

\section{Anatomical definition of the critical region of the interpositus} nucleus. Based on the now-extensive literature showing lesions of the interpositus nucleus that are completely effective in abolishing the eye blink $C R$, we can define rather precisely the critical region. Using kainic acid lesions that do not cause degeneration in the inferior olive, the critical region is the dorsolateral aspect of the anterior one-third of the interpositus nucleus and is not much larger than a cubic millimeter (Lavond et al., 1985). This region receives somatotopic projections representing the eye from the dorsal accessory olive (Gibson et al., 1987) and projects to the red nucleus (Rosenfield et al., 1985). Because of interanimal variability and the variability inherent in the stereotaxic method, a substantially larger lesion is generally used to abolish the $\mathrm{CR}$ reliably across animals. The electrolytic lesion procedure described for experiment II (Materials and Methods) yields such a lesion.

Welsh and Harvey claim that anatomically comparable lesions of the interpositus can either completely or incompletely abolish the CR. Although they do not provide sufficient anatomical data in their report to establish this claim, Welsh does provide these data for 12 "effective" lesion animals in his thesis (Welsh, 1987). One of us (D.G.L.) examined Welsh's lesion reconstructions blind insofar as behavioral effects were concerned. In only one animal did the lesion appear to have completely destroyed the critical region of the interpositus. Lesions were almost complete in five animals, more incomplete in two, and even more incomplete in four animals. Since Wclsh and Harvey do not identify the animals in their report either in terms of lesion or performance, we cannot match them, but the fact that most of the lesions did not completely destroy the critical region of the interpositus nucleus accounts for their results.

\section{Effects of interpositus lesions on the UR}

Our results demonstrate that the interpositus lesion effective in completely abolishing the CR has no persisting effects on the UR to US-alone stimuli over a range of US intensities. Interestingly, the UR to the US of the training intensity does show a decrease immediately following lesion but it quickly recovers to the preoperative level.

As noted earlier, Welsh and Harvey did not in fact measure the effects of interpositus lesions on reflex responses in the same animals; instead, they compared only some of their postlesion animals scparated post hoc into different groups. Importantly, they did not find any effect of interpositus lesions on amplitude of the UR at any US intensity. Our data, and their data, on effect of US intensity, per se, on properties of the UR indicate clearly that amplitude of the UR is an appropriate measure of UR performance but peak latency and rise time of the UR are not; unlike amplitude, they do not vary with US intensity. Welsh and Harvey report only very small lesion effects on UR peak latency and rise time (and UR frequency) at low US intensities. We do not see any such effects. Many factors can influence the UR, and there are extreme individual animal differences in properties of the UR. In order to demonstrate effects of lesions on the UR, it is essential to compare URs in the same animals before and after lesion.

Welsh and Harvey (1989a) assert that, "when one attempts to equate the CS and the UCS as response-eliciting stimuli, the deficits in the CR and the UCR become morc alike" (p 309). The only way to evaluate this statement is to equate the CS and the US in terms of response elicitation prior to lesion and then determine the effect of the lesion on the two responses that were "psychophysically equivalent" prior to lesion. Welsh and Harvey do not make this comparison and do not provide any information on the properties of the URs prior to lesion in their animals. We do have such data. Indeed, the UR amplitude at $1 \mathrm{psi}$ is lower than the CR amplitude, and the frequency of both is the same prior to lesion; the CS and US are "equated as response eliciting stimuli" (actually, the CS is a somewhat stronger "response eliciting stimulus" than the US) (see Fig. 15A). After lesion, there is no appreciable change in the UR amplitude or frequency at $1 \mathrm{psi}$, but the CR amplitude is reduced to virtually zero in amplitude and frequency.

Although Welsh and Harvey do not provide any data on prelesion URs to US-alone tests, wc can use their "no lesion effect" group for this measure. Following their requirement, it 

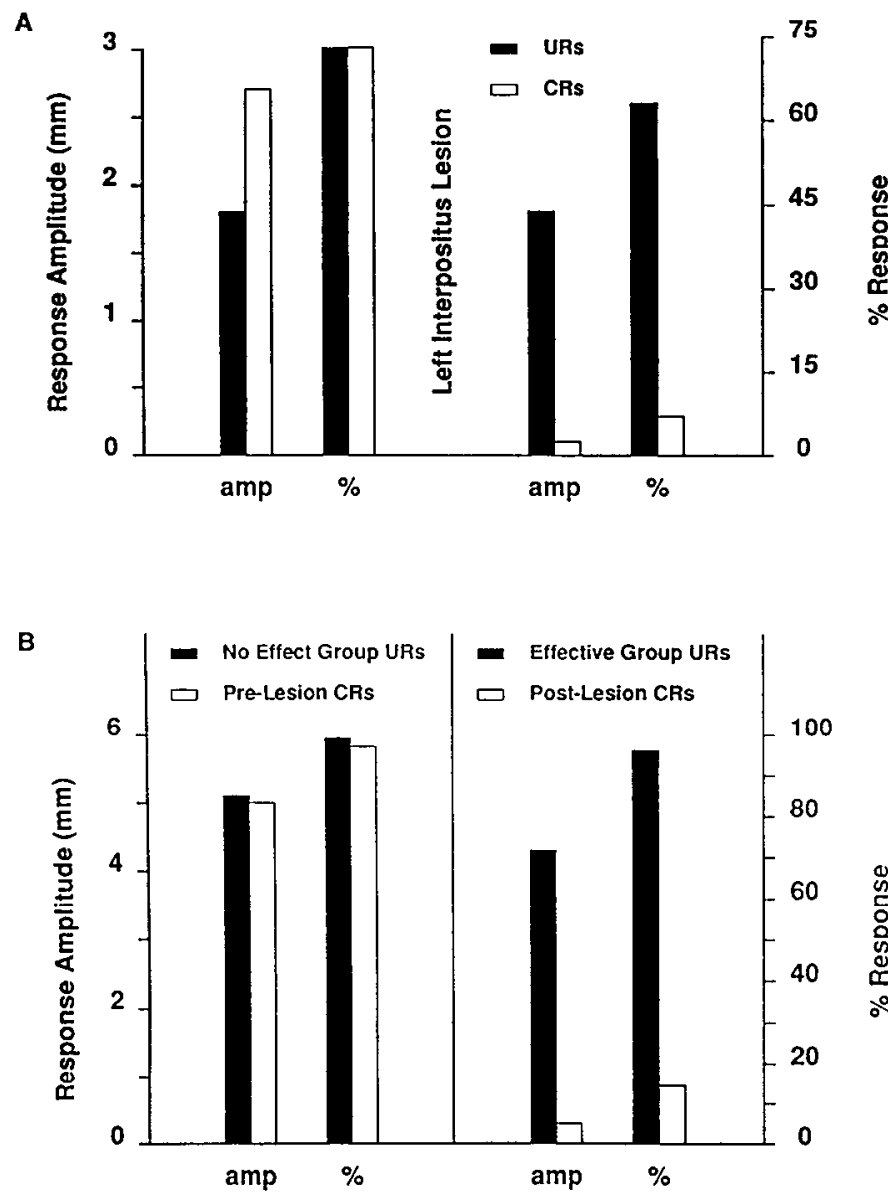

Figure 15. A, Response amplitudes and percentages of responses (solid bars) to 1 psi US-alone stimulus presentations and CR amplitudes and percentage of responses (open bars; trained with a 3 psi US) recorded before and after cerebellar interpositus lesions. $B$, Responses recorded during Welsh and Harvey's (1989a) study that have been equated for amplitude and frequency. On the left are shown UR amplitudes and percentage of responses recorded from "noneffectively" lesioned rabbits (solid bars) and prelesion CR amplitudes and percentage of responses (open bars). On the right are shown UR amplitudes and percentage of responses (solid bars) and postlesion CR amplitudes and percentage of responses recorded from "effectively" lesioned rabbits (open bars).

is necessary to equate the CS and US as response eliciting stimuli, that is, to select the US intensity in the "no effect" group that yields a response "psychophysically equivalent" to the CR prior to lesion. Results are shown in Figure $15 B$, where the responses arc cquated in amplitude and frequency. Note that the properties of the prelesion CR and the "no effect" UR are identical. Note also a profound reduction in mean amplitude and frequency of the CR postlesion but no difference at all in UR mean amplitude or frequency between the "effective" and "no effect" groups.

The comparison Welsh and Harvey make, that is, between CR amplitudes postlesion and UR amplitudes postlesion at the lowest-intensity US, is logically indefensible. Our animals showed zero mean amplitude $C R s$ postlesion when compared to normal control animals given unpaired CS-US training. The intensity of the US to yield a zero response amplitude UR would have to be set at zero to equate the postlesion CS and US as "response eliciting stimuli." This is just another way of saying that the lesion completely abolished the CR but had no effect on the UR. Interestingly, Welsh and Harvey's data contradict their assertion, even with the indefensible comparison they make: the mean amplitude of the CR in their "effective" lesion group is three times smaller than the mean amplitude of the postlesion UR at the lowest US intensity, and the frequency of occurrence of the CR is three times lower than the frequency of occurrence of the UR. ${ }^{3}$ Actually, it is not at all clear that the CS and US can be "equated as response eliciting stimuli" for the simple reason that the $C R$ and the UR differ fundamentally in a number of ways (see below).

\section{The nature of the $C R$}

There appears to be some confusion in the literature regarding the nature of the conditioned eye blink response. Thus, Welsh and Harvey (1989a) stated that "both the CR and the UCR are expressed by the same final common pathway consisting of the retractor bulbi motor neurons in the accessory abducens nucleus and their projections to the retractor bulbi muscle via the VI cranial nerve" (p 309). This statement is not correct. Gormezano and associates showed some years ago in separate studies of the rabbit that eyeball retraction, NM extension, and external eyelid closure all had essentially identical acquisition functions (Gormezano et al., 1962; Schneiderman et al., 1962; Deaux and Gormezano, 1963). We recorded simultaneously NM extension and external eyelid closure (EMG recordings from orbicularis oculi) during acquisition and extinction and showed that they were in essence perfectly correlated (McCormick et al., 1982). Lavond et al. (1990) recently replicated and extended these observations. Furthermore, some degree of conditioned contraction of facial and neck musculature also developed, again highly correlated with NM extension. These observations led us to characterize the conditioned response as a "synchronous facial 'flinch' centered about closure of the eyelids and extension of the NM" (McCormick et al., 1982c, p 773).

Several laboratories have recorded neuronal unit activity from motor nuclei during eye blink conditioning. Substantial learning-induced increases in neuronal unit activity that correlate very closely with the conditioned NM extension response have been reported in the following motor nuclei: oculomotor, trochlear, motor trigeminal, abducens, accessory abducens, and facial (e.g., Cegavske et al., 1979; Berthier and Moore, 1983; McCormick et al., 1983; Disterhoft et al., 1985). In terms of magnitude of increase, the region of the facial nucleus innervating the orbicularis oculi muscles (external eyelid closure) shows the greatest engagement (McCormick et al., 1983). Similarly, EMG recorded from the orbicularis oculus muscle shows a much greater magnitude of increase over the course of learning than does the NM extension responsc, as notcd above (McCormick et al., 1982c; Lavond et al., 1990a). However, these are all components of the same global CR involving, to the extent studied, essentially perfectly coordinated activity in a number of muscles and associated motor nuclei. Where studied, as in NM extension and orbicularis oculi EMG, this virtually perfect correlation $(r$ $=0.95$ ) holds both for the occurrence of a CR within a trial and

\footnotetext{
${ }^{3}$ So far as we can determine, Welsh and Harvey calculated CR mean amplitude as the sum of amplitudes of CRs greater than $0.5 \mathrm{~mm}$ divided by the number of CRs greater than $0.5 \mathrm{~mm}$, a measure sometimes termed CR magnitude. We use the conventional method for calculating mean amplitude, that is, the sum of amplitudes for all CRs greater than $0.5 \mathrm{~mm}$ divided by the total number of trials. The magnitude measure is greatly influenced by spontaneous responses, particularly when scored only for CS-alone test trials: with six test trials in a session, one spontaneous response of $2.9 \mathrm{~mm}$ on only one trial would be scored as a mean magnitude of $2.9 \mathrm{~mm}$ for the session but a mean amplitude of $0.48 \mathrm{~mm}$ for the session. Here, we recalculated their magnitude measures as amplitude measures.
} 
in terms of the development of learning-induced CR activity over the trials of training (e.g., McCormick et al., 1982c). The NM extension response is but one component of the CR. The suggestion that different motor nuclei might somehow exhibit "different" CRs in the eye blink conditioning paradigm (Delgado-Garcia et al., 1990) is not supported by evidence.

Insofar as efferent control of the NM extension response in rabbit is concerned, NM extension, per se, is due to retraction of the eyeball (Cegavske et al., 1976). This is often stated to be due solely to the action of the retractor bulbi muscles (e.g., Welsh and Harvey, 1989a). Such is not entirely the case. Although it is the major action producing eyeball retraction in species that have a functional NM, all species studied exhibit eye retraction regardless of whether they have a retractor bulbi muscle (Evinger ct al., 1984). Other cxtraocular muscles also participate (Disterhoft et al., 1987; Delgado-Garcia et al., 1990). Further, the view that in animals with a functional NM (e.g., rabbit, cat) the retractor bulbi muscle is innervated solely by the accessory abducens nucleus is not entirely correct; it is also innervated by motor neurons from the abducens (Cegavske et al., 1987; Delgado-Garcia et al., 1990).

The CR and the UR are similar in eye blink conditioning in the sense that to a large extent the same muscles and motor nuclei are engaged. However, the CR and the UR differ fundamentally in a number of respects. Thus, under the conditions of our experiments, the minimum onset latency of the CR to a tone $\mathrm{CS}$ in well-trained rabbits, measured as NM extension, is about $100 \mathrm{msec}$; the minimum onset latency of the NM extension UR in the rabbit to a 3 psi air puff US is about $25-40 \mathrm{msec}$. Perhaps most important, the variables that determine the topographies of the UR and CR are completely different. The topography of the UR is under the control of the properties of the US-stimulus intensity, rise time, and duration. In marked contrast, the topography of the CR is virtually independent of the properties of the US and is largely determined by the ISI, the CS-US onset interval, the CR peaking at about the onset of the US over a wide range of effective CS-US onset intervals (Schneiderman, 1966; Coleman and Gormezano, 1971; Millenson et al., 1977; Steinmetz, 1990a). This key property of the CR cannot be derived from the properties of the US or the UR. The CR and the UR also differ in that certain components of the UR can be elicited separately by appropriate peripheral stimuli but the CR always occurs as a global coordinated response (McCormick et al., 1982c). Another important difference is that the CR exhibits much greater plasticity in recovery from lesions that impair performance of the UR than does the UR itself (see Disterhoft ct al., 1985, and expcriment III, above).

In sum, the conditioned eye blink response involves highly coordinated activity in a number of motor nuclei and muscles; it is one global defensive response that is conditioned to a neutral stimulus as a result of associative training. The very small lesion of the interpositus nucleus that is effective in completely and permanently abolishing the conditioned NM extension response also completely and permanently abolishes all other components of the $C R$ that have been studied-eyeball retraction, external eyelid closure, orbicularis oculi EMG - without producing any persisting impairment in performance of the reflex response.

\section{The issue of performance}

Classical conditioning has been the favored behavioral paradigm for neurobiological analysis of basic associative learning and memory in both invertebrate preparations (e.g., Carew et al., 1983; Walters and Byrne, 1983; Alkon, 1984; Crow, 1985) and vertebrate preparations (e.g., Berger and Thompson, 1978; Cohen, 1984; Disterhoft et al., 1985; Donegan et al., 1985; Davis et al., 1987; Powell et al., 1990; Steinmetz and Thompson, 1991). It has a number of advantages, including a high degree of experimenter control of stimulus presentations and response elicitation, precision of behavioral measurement, and so on, which have been detailed many times (e.g., Kandel, 1976; Thompson et al., 1976; Gormezano et al., 1983; Patterson and Romano, 1987). A particular advantage of classical conditioning is that performance of the behavioral response, per se, can be measured independently of the performance of the learned response. Thus, behavioral and biological variables that influence the learned response, the $\mathrm{CR}$, can be assayed for the possibility that they do so by general or nonspecific effects on behavioral performance by measuring effects on the UR. This has been demonstrated in careful studies by Gormezano and associates and others concerned with effects of drugs on learning and memory (Gormezano and Harvey, 1980; Mauk et al., 1982; Schindler et al., 1984; Sears and Steinmetz, 1990b; Kirkpatrick-Steger et al., 1991). Drugs such as morphine, sodium pentobarbital, and haloperidol that can profoundly impair acquisition and performance of CRs do so at appropriate doses in the absence of any effects on performance of the UR. This general result rules out the possibility that such drugs exert their influence on the $C R$ simply by impairing the ability of the animal to perform the behavioral response.

A striking aspect of the many published studies on effects of interpositus lesions on the classically conditioned eye blink response and the present experiments is that the lesion completely abolishes the CR and has no cffect on the UR. Results of experiment III and the study by Disterhoft et al. (1985) demonstrate that lesions causing a profound and permanent impairment in the performance of the UR itself cause relatively little long-lasting impairment in the performance of the CR. In this instance, the $\mathrm{CR}$ recovery is likely due to compensation via increased activation of other extraocular muscles and perhaps from abducens motor neurons following damage to the accessory abducens nucleus. The animal is still able to achieve the necessary adaptive learned response.

An interesting outcome of experiments II and III is the considerable plasticity exhibited by the UR itself. The increase in UR amplitude over training has actually been noted in a number of studies but usually where US-alone trials have not been given; in paired CS-US trials the development of the CR can add to the apparent UR amplitudes. However, experiment II suggests that this increase over training is not associative but merely the result of repeated exposure to the stimuli. One possible explanation is habituation of the orienting response, which includes increased opening of the eye to novel stimuli. Importantly, the interpositus lesion does not abolish this experience dependent increase in the UR. The present results are consistent with other reports of plasticity of the eye blink UR, for example, as a result of eyelid loading or reflex facilitation (e.g., Evinger and Manning, 1988; Weisz and LoTurco, 1988). However, the plasticity in recovery shown by the UR is much less than the plasticity shown by the $\mathrm{CR}$ in recovery following damage to motor nuclei involved in generating performance of the UR and CR. This result demonstrates that very small changes in the UR at very low US intensities of the sort claimed by Welsh and Harvey cannot possibly have any appreciable effect on performance of the CR. 
Lesions of cerebellar cortex have impaired or abolished the conditioned eye blink response (Yeo et al., 1985b; Lavond et al., 1987; Lavond and Steinmetz, 1989b). These same lesions may actually cause a substantial and significant increase in the amplitude of the eye blink UR (e.g., Yeo and Hardiman, 1988; Logan, 1991). Therc is thus a double dissociation between lesion effects on the CR and the UR: accessory abducens lesions massively impair the UR but not the CR, and lesions of cerebellar cortex can massively impair the CR but increase the UR. Lesions of the interpositus nucleus completely abolish the CR with no persisting effect on the UR. The performance argument, that interpositus lesions abolish the CR by impairing the UR, is therefore decisively negated. We did note a transient decrease in the UR immediately following interpositus lesions at the training US intensity in experiment II, but this quickly recovered to preoperative levels. Some transient decrease might be expected since the interpositus lesion removes some of the polysynaptic excitatory drive to motor nuclei, but rapid recovery would also be expected given the adaptive plasticity of reflex motor systems to altered afference (Ito, 1984; Lisberger, 1984).

One other statement by Welsh and Harvey (1989a) requires comment: "We have recently found that infusion of the local anesthetic Lidocaine into the area of the anterior interpositus produced reversible deficits in the performance of both the conditioned and unconditioned NMR. These results clearly indicate that lesions including the anterior interpositus produce a generalized deficit in the performance of the NMR. There is no experimental evidence to indicate that there might be a learning deficit embedded within this performance deficit" (pp 309-310). In this discussion, they fail to cite our earlier study showing just the opposite result (Mamounas et al., 1987). We demonstrated that microinfusion of very small amounts of GABA antagonists in the anterior interpositus completely and reversibly abolished the eye blink $C R$ and had no effect at all on the UR in a dosedependent fashion; a dose of $0.7 \mathrm{nmol}$ of picrotoxin produced this effect. Further, the effect was extremely localized anatomically. The relatively large amount of lidocaine infused by Welsh and Harvey (1989b) would likely inactivate a substantial amount of the interpositus. Also, lidocaine is not selective in inhibiting neural activity. Iidocaine infusion could therefore cause a transient decrease in excitability of target motor nuclei since all output from the interpositus would be temporarily blocked. Our evidence had already demonstrated that specific neurotransmitter antagonists can exert a highly specific and localized action in the interpositus resulting in complete abolition of the $\mathrm{CR}$ with no effect at all on the UR. There is in fact no evidence at all to support the claim that the abolition of the eye blink CR by lesion of the interpositus is due in any way to effects on performance.

If, as Welsh and Harvey claim, the interpositus lesion has not damaged the "real" memory trace circuit, the animals ought to relearn the response rapidly. The lesion-memory literature is replete with examples of rapid recovery of learned responses following lesions that initially impair the performance of the learned response (for reviews, see Lavond et al., 1984b; Finger et al., 1988). Indeed, we showed a striking example of such recovery for the eye blink CR following noncerebellar lesions in experiment III of this article. The fact that there is never any recovery of the eye blink CR following effective interpositus lesions, or even from partially effective lesions, is virtually unique in the lesion-memory literature and a strong argument for inferring that the interpositus nucleus is a part of the essential memory trace circuit for eye blink conditioning. Apparently, the hypothetical noncerebellar memory trace circuit proposed by Welsh and Harvey does not function as a memory trace circuit after effective interpositus nucleus lesions since eye blink CRs are not retained after the lesion.

\section{The role of the cerebellum in eye blink conditioning}

Evidence to date demonstrates that the cerebellum is necessary for both learning and memory of classical conditioning of the eye blink response and, to the extent tested, other discrete skeletal muscle responses, learned with an aversive US. We reviewed the lesion evidence above (see introductory remarks). In brief, lesions of the following structures cause immediate, complete, and, where tested, permanent abolition of the eye blink CR and have no effect on the reflex response: pontine nuclei, middle cerebellar peduncle, anterior interpositus nucleus, superior cerebellar peduncle, magnocellular red nucleus, and descending rubral pathways. Where tested, these same lesions completely prevent acquisition of the CR.

As summarized below, all evidence to date supports the hypothesis that the memory traces for eye blink conditioning are formed in the cerebellum, that the CS pathway involves mossy fibers and the US pathway involves climbing fibers, and that the memory traces are formed by neurons in the cerebellum receiving converging activation from the CS (mossy-parallel fiber) and the US (climbing fiber) pathways.

Electrical stimulation of the pontine nuclei serves as a "supernormal" CS, yielding more rapid learning than does a tone or light CS (Steinmetz et al., 1986). With a pontine stimulation $\mathrm{CS}$, lesion of the middle cerebellar peduncle abolishes the CR, ruling out the possibility that the pontine $\mathrm{CS}$ is activating noncerebellar pathways, for example, by stimulation of fibers of passage or antidromic activation of sensory afferents (Solomon et al., 1986a). Stimulation of the middle cerebellar peduncle itself is an effective CS, and lesion of the interpositus nucleus abolishes the CR established with a pontine or middle peduncle stimulation CS (Steinmetz et al., 1986). Localized lesions of the pontine nuclei can abolish the CR to a tone CS but not a light CS (i.e., can be selective for CS modality) (Steinmetz et al., 1987). Finally, when animals are trained using electrical stimulation of the pontine nuclei as a CS (corneal air puff US), some animals show immediate and complete transfer of the behavioral eye blink CR and the learning-induced neuronal model of the behavioral CR in the interpositus nucleus to a tone CS, arguing that the pontine stimulus and tone must activate a large number of memory trace elements (neurons) in common (Steinmetz, 1990b). In comparison, there is less transfer when animals are trained and tested on disparate peripheral CSs, for example, tone and light (e.g., Steinmetz et al., 1987). These results all support the mossy fiber CS hypothesis.

As noted in the introductory remarks, lesions of the face region of the DAO prevent acquisition of the contralateral eye blink CR if made before training and result in extinction and abolition of the CR in previously trained animals (McCormick et al., 1985). Electrical microstimulation of this region of the DAO elicits eye blink responses before training; indeed, virtually any phasic behavioral response can be so elicited, depending on the locus of the stimulating electrode. When DAO stimulation is used as a US, the exact response elicited by DAO stimulation is learned as a CR to a tone CS. Control procedures demonstrated that the stimulus was activating climbing fibers to the cerebellum (Mauk et al., 1986). Further, movements elicited 
from stimulation of the adjacent reticular formation could not be conditioned to a CS. Lesion of the interpositus nucleus abolished both the CR and the UR elicited by DAO stimulation, thus ruling out the possibility that the UR is elicited by antidromic activation of reflex afferents. As demonstrated at length in the present article, interpositus lesions effective in abolishing the CR have no effect on the reflex UR to the corneal air puff US.

Neuronal unit activity recorded in the critical region of the DAO exhibits no responses at all to the tone CS and a clear evoked increase in unit activity to onset of the corneal air puff US prior to learning. Interestingly, this US-evoked neuronal activity decreases as animals learn and perform the CR but is still fully present in US-alone trials (Sears and Steinmetz, 1991). All of these results together support the hypothesis that the US pathway includes neurons of the DAO and their climbing fiber projection to the cerebellum. They also rule out the possibility that the memory trace is localized to the DAO-neurons that form the associative memory trace must received input from both the CS (tone) and US (corneal air pum).

As noted in the introductory remarks, recordings of neuronal unit activity from the region of the anterior interpositus nucleus necessary for learning and memory of the eye blink CR exhibit evoked unit activity to both the CS and US and learning-induced increases in discharge frequency that precede and predict the occurrence of the behavioral CR both within trials and over the trials of training (Foy et al., 1984; McCormick and Thompson, 1984b; Berthier and Moore, 1990). In well-trained animals, this Icarning-induced increase in unit activity is virtually isomorphic with the behavioral CR in amplitude-time course form, except having a substantially shorter onset latency than the behavioral CR.

Electrical microstimulation of the critical region of the anterior interpositus nucleus evokes an eye blink response in naive animals, and lesion of the superior cerebellar peduncle abolishes this response; the eye blink circuit is hard wired from interpositus nucleus to behavior (McCormick and Thompson, 1984b). If the stimulus intensity is set to elicit an eye blink comparable in amplitude to that elicited by our standard 3 psi corneal air puff and this interpositus stimulus is used as a US, neither learning of the CR to a tone CS nor maintenance of a CR previously learned to tone with a corneal air puff US occurs. However, animals given tone-interpositus training show marked transfer in subsequent tone-air puff training (Chapman et al., 1988).

The region of the magnocellular red nucleus that receives projection from the critical region of the anterior interpositus also exhibits a learning-induced pattern of increased unit activity in eye blink conditining very similar to that shown by interpositus neurons. As noted in the introductory remarks, lesion or reversible inactivation of this region of the red nucleus abolishes the eye blink CR and has no effect on the reflex UR (Haley et al., 1988). Microstimulation of this region of the red nucleus in naive animals also elicits eye blink responses. When this is used as a US, neither learning of the CR to a tone CS nor maintenance of a $C R$ previously learned with tone-air puff training occurs. Further, there is no transfer from tone-red nucleus training to subsequent tone-air puff training (Chapman et al., 1988). If the red nucleus is reversibly inactivated, the eye blink $\mathrm{CR}$ is reversibly abolished but the learning-induced neuronal modcl of the CR in the interpositus nucleus is unaffected (Chapman et al., 1990). In contrast, when the anterior interpositus nucleus is reversibly inactivated, both the behavioral $\mathrm{CR}$ and the learning-induced neuronal model of the $C R$ in the magnocellular red nucleus are completely abolished. All this evidence supports the hypotheses that the eye blink CR circuit is hard wired from interpositus to behavior, and that the memory trace is not in the red nucleus and is at or before the interpositus nucleus in the circuit.

Purkinje neuron activity in the eye blink conditioning paradigm supports the cerebellar hypothesis. Many Purkinje neurons, particularly in HVI, are responsive to the tone CS and the corneal air puff US in naive animals. Before training, the majority of Purkinje neurons that are responsive to the tone show variable increases in simple spike discharge frequency in the CS period (Foy and Thompson, 1986). After training, the majority show learning-induced decreases in simple spike frequency in the CS period; however, a significant minority show the opposite effect (Donegan et al., 1985; Foy and Thompson, 1986; Thompson, 1990). In current and preliminary work, it appears that the two types of learning-induced simple spike responses in the CS period may be from different functional microzones of cerebellar cortex.

Before training, Purkinje neurons that are influenced by the corneal air puff consistently show an evoked complex spike to US onset. In trained animals, this US evoked complex spike is virtually absent on paired CS-US trials when the animal gives a CR but present and normal on US-alone test trials (Berthier and Moore, 1986; Foy and Thompson, 1986; Krupa et al., 1991). This learning-induced reduction in US-evoked complex spikes led to the D $\Lambda O$ unit recording study noted above (Sears and Steinmetz, 1991). The lack of US-evoked DAO activity after CRs have been established accounts for the lack of US-evoked climbing fiber activity observed after training.

Latency measures are consistent with the cerebellar hypothesis. Under the conditions of our experiments $(85 \mathrm{~dB}$ tone $\mathrm{CS}$, 3 psi corneal air puff, $250 \mathrm{msec}$ CS-US onset interval), the mean minimum onset latency of the NM extension CR is about 100 msec. (The mean minimum onset of the orbicularis oculi EMG response is $10-20 \mathrm{msec}$ shorter, mechanical lags presumably accounting for most of the difference.) The onset of learninginduced unit activity in the interpositus nucleus varies somewhat from animal to animal; it can precede onset of the learned NM response by as much as $60-70 \mathrm{msec}$, and a typical value is about 50 msec. Learning-induced decreases in Purkinje neuron simple spikes can precede the onset of the learned NM response by as much as 60-80 msec (Foy and Thompson, 1986). The latency of activation of the cerebellum by peripheral somatosensory stimuli is about $20 \mathrm{msec}$ (Ekerot et al., 1987). Finally, onset of the NM extension response to electrical stimulation of the interpositus nucleus is about $50 \mathrm{msec}$ (McCormick and Thompson, 1984a). These time delays account perfectly for the otherwise puzzling fact that the minimum onset latency of the conditioned NM response is about $100 \mathrm{msec}$, substantially longer than the minimum onset latency of the reflex NM response to corneal air puff $(25 \mathrm{msec})$, and the even more puzzling fact that no learning occurs if the CS-US onset interval (the ISI used in training) is shorter than about $80 \mathrm{msec}$ (e.g., Gormezano et al., 1983; Steinmetz, 1990a).

When electrical microstimulation of the pontine nuclei or middle cerebellar peduncle is used as a CS and microstimulation of the critical region of the DAO that elicits eye blinks is used as a UR, animals learn the classically conditioned eye blink response in a normal fashion (Steinmetz et al., 1988). This result 
argues very strongly that at least under these conditions the memory trace is stored in the cerebellum. This finding, together with the fact that learning results in decreases in Purkinje neuron simple spike discharges in the CS period, supports the hypothesis that a process like long-term depression may be a mechanism of synaptic plasticity in cerebellar cortex in eye blink conditioning (Ito, 1984).

In summary, the evidence cited above demonstrates beyond all reasonable doubt that the cerebellum and its associated brainstem circuity are necessary for classical conditioning of the eye blink and other discrete behavioral responses. The evidence also supports the stronger hypothesis that the cerebellum and its associated brainstem circuity are the essential (necessary and sufficient) circuitry for such learned responses. We are aware of no convincing evidence against these hypotheses. Indeed, there is as yet no noncerebellar hypothesis that can account for even a small part of the evidenced cited above. All the evidence supports the still stronger hypothesis that the memory traces for classical conditioning of eye blink and other discrete responses are formed and stored in the cerebellum. However, this hypothesis is not yet proved. A related issue, still unresolved, concerns the relative roles of cerebellar cortex and interpositus nucleus in such memory trace formation. These issues are amenable to experimental analysis. Thus, if learning fails to occur when training is given during reversible inactivation of critical regions of the cerebellum, it would be strong evidence favoring cerebellar memory trace formation. Lavond and associates have obtained just such evidence: eye blink training (tone $\mathrm{CS}$ ) given during reversible cooling of cerebellar tissue results in no learning (Lavond et al., 1990b). Welsh and Harvey (1989b) claimed that training to a tone CS during lidocaine infusion in the cerebellum in animals previously trained to a light CS results in learning to the tone. However, we find that lidocaine infusion in the cerebellum during training to a tone CS in naive animals prevents acquisition in a dose-dependent manner ( $R$. F. Thompson, unpublished observations). Finally, we note that the basic cerebellar lesion result we first reported using rabbits (McCormick ct al., 1981) has now becn replicated in rats (Skclton, 1988) and in humans (Lye et al., 1988; Solomon et al., 1989). It is therefore reasonable to infer that all the evidence summarized above applies to all mammals, including humans.

\section{The cerebellum and motor learning}

The eye blink CR is an elementary learned, skilled movement. The general hypothesis that the cerebellum is critically involved in motor skill learning and the more specific hypothesis that the memory traces for learned motor skills are stored in the cerebellum have a long and distinguished history (Brindley, 1964; Eccles et al., 1967; Marr, 1969; Albus, 1971; Gilbert, 1974; Eccles, 1977; Ito, 1984). All the evidence cited in the present article regarding the role of the cerebellum in eye blink conditioning supports these hypotheses. This article is not the appropriate place to review the vast literature relevant to these hypotheses. We simply note that there is extensive recent supportive clinical evidence (Sanes et al., 1990). We also note that Thach and associates (e.g., Thach et al., 1992) have recently developed a comprehensive empirical-theoretical analysis of the cerebellum in the adaptive coordination of movement. This analysis accounts for clinical syndromes resulting from cerebellar damage and argues compellingly that the cerebellum is critically involved in motor learning and that the momory traces for specific learned motor synergies are stored in the cerebellum.

\section{References}

Akase E, Alkon DL, Disterhoft JF (1989) Hippocampal lesions impair memory of short-delay conditioned eye blink in rabbits. Behav Neurosci 103:935-943.

Albus JS (1971) A theory of cerebellar function. Math Biosci 10:2561.

Alkon DL (1984) Calcium-mediated reduction of ionic currents: a biophysical memory trace. Science 225:1037-1045.

Berger TW, Orr WB (1983) Hippocampectomy selectively disrupts discrimination reversal conditioning of the rabbit nictitating membrane response. Behav Brain Res 201:411-417.

Berger TW, Thompson RF (1978) Neuronal plasticity in the limbic system during classical conditioning of the rabbit nictitating membrane response. I. The hippocampus. Brain Res 145:323-346.

Berger TW, Weikert CL, Bassett JL, Orr WB (1986) Lesions of the retrosplenial cortex produce deficits in reversal learning of the rabbit niclitaling membrane response: implications for potential interactions between hippocampal and cerebellar brain systems. Behav Neurosci 100:802-809.

Berthier NE, Moore JW (1983) The nictitating membrane response: an electrophysiological study of the abducens nerve and nucleus and the accessory abducens nucleus in rabbit. Brain Res 258:201-210.

Berthier NE, Moore JW (1986) Cerebellar Purkinje cell activity related to the classically conditioned nictitating membrane response. Exp Brain Res 63:341-350.

Berthier NE, Moore JW (1990) Activity of deep cerebellar nuclear cells during classical conditioning of nictitating membrane extension in rabbits. Exp Brain Res 83:44-54.

Brindley GS (1964) The use made by the cerebellum of the information that it receives from sense organs. IBRO Bull 3:30.

Carew TJ, Hawkins RD, Kandel ER (1983) Differential classical conditioning of a defensive withdrawal reflex in Aplysia californica. Science 219:397-400.

Cegavske CE, Thompson RF, Patterson MM, Gormezano I (1976) Mechanisms of efferent neuronal control of the reflex nictitating membrane response in the rabbit. J Comp Physiol Psychol 90:411-423.

Cegavske CF, Patterson MM, Thompson RF (1979) Neuronal unit activity in the abducens nucleus during classical conditioning of the nictitating membrane response in the rabbit (Oryctolagus cuniculus). J Comp Physiol Psychol 93:595-609.

Cegavske CF, Harrison TA, Torigoe Y (1987) Identification of the substrates of the unconditioned response in the classically conditioned, rabbit, nictitating-membrane preparation. In: Classical conditioning, 3d ed (Gormezano I, Prokasy WF, Thompson RF, eds), pp 65-94. Hillsdale, NJ: Erlbaum.

Chapman PF, Steinmetz JE, Thompson RF (1988) Classical conditioning does not occur when direct stimulation of the red nucleus or cerebellar nuclei is the unconditioned stimulus. Brain Res 442:97104.

Chapman PF, Steinmetz JE, Sears LL, Thompson RF (1990) Effects of lidocaine injection in the interpositus nucleus and red nucleus on conditioned behavioral and neuronal responses. Brain Res 537:149156.

Clark GA, McCormick DA, Lavond DG, Thompson RF (1984) Effects of lesions of cerebellar nuclei on conditioned behavioral and hippocampal neuronal response. Brain Res 291:125-136.

Cohen DH (1984) Identification of vertebrate neurons modified during learning: analysis of sensory pathways. In: Primary neural substrates of learning and behavioral change (Alkon DL, Farley J, eds), pp 129 154. London: Cambridge UP.

Coleman SR, Gormezano I (1971) Classical conditioning of the rabbit's (Oryctolagus cuniculus) nictitating membrane response under symmetrical CS-US interval shifts. J Comp Physiol Psychol 77:447455.

Crow T (1985) Conditioned modification of phototactic behavior in Hermissenda: differential light adaptation of B-photoreceptors. J Neurosci 5:215-223.

Davis M, Hitchcock JM, Rosen JB (1987) Anxiety and the amygdala: pharmacological and anatomical analysis of the fear-potentiated startle paradigm. In: The psychology of learning and motivation (Bower GH, ed), pp 263-305. New York: Academic.

Deaux EG, Gormezano I (1963) Eyeball retraction: classical conditioning and extinction in the albino rabbit. Science 141:630-631.

Delgado-Garcia JM, Evinger C, Escudero M, Baker R (1990) Behavior 
of accessory abducens and abducens motoneurons during eye retraction and rotation in the alert cat. J Neurophysiol 64:413-422.

Disterhoft JF, Quinn KJ, Weiss C, Shipley MT (1985) Accessory abducens nucleus and conditioned eye retraction nictitating membrane extension in rabbit. J Neurosci 5:941-950.

Disterhoft JF, Quinn KJ, Weiss C (1987) Analyses of the auditory input and motor output pathways in rabbit nictitating membrane conditioning. In: Classical conditioning, 3d ed (Gormezano I, Prokasy WF, Thompson RF, eds), pp 93-116. Hillsdale, NJ: Erlbaum

Donegan NH, Lowry RW, Thompson RF (1983) Effects of lesioning cerebellar nuclei on conditioned leg-flexion responses. Soc Neurosci Abstr 9:331.

Donegan NM, Foy MR, Thompson RF (1985) Neuronal responses of the rabbit cerebellar cortex during performance of the classically conditioned eyelid response. Soc Neurosci Abstr 11:835.

Eccles JC (1977) An instruction-selection theory of learning in the cerebellar cortex. Brain Res 127:327-352.

Eccles JC, Ito M, Szentagothai J (1967) The cerebellum as a neuronal machine. New York: Springer.

Ekerot CF, Gustavsson P, Oscarsson O, Schouenborg J (1987) Climbing fibres projecting to cat cerebellar anterior lobe activated by cutaneous A and C fibres. J Physiol (Lond) 386:529-538.

Evinger C, Manning KA (1988) A model system for motor learning: adaptive gain control of the blink reflex. Exp Brain Res 70:527-538.

Evinger C, Shaw MD, Peck CK, Manning KA, Baker R (1984) Blinking and the associated eye movements in humans, guinea pigs, and rabbits. J Neurophysiol 52:323-339.

Finger S, LeVere TE, Almli CR, Stein DG (1988) Brain Injury and recovery: theoretical and controversial issues. New York: Plenum.

Foy MR, Thompson RF (1986) Single unit analyses of Purkinje cell discharge in classically conditioned and untrained rabbits. Soc Neurosci Abstr 12:518.

Foy MR, Steinmetz JE, Thompson RF (1984) Single unit analysis of the cerebellum during classically conditioned eyelid responses. Soc Neurosci Abstr 10:122.

Gibson AR, Robinson FR, Alam J, Houk JC (1987) Somatotopic alignment between climbing fiber input and nuclear output of the cat intermediate cerebellum. J Comp Ncurol 260:362-377.

Gilbert PFC (1974) A theory of memory that explains the function and structure of the cerebellum. Brain Res 70:1-18.

Gormezano I, Harvey JA (1980) Sensory and associative effects of LSD in classical conditioning of the rabbit (Oryctolagus cuniculus) nictitating membrane response. Psychopharmacology (Berl) 70:137143.

Gormezano I, Schneiderman N, Deaux EG, Fuentes I (1962) Nictitating membrane: classical conditioning and extinction in the albino rabbit. Science 138:33-34.

Gormezano I, Kehoe EJ, Marshall-Goodell BS (1983) Twenty years of classical conditioning research with the rabbit. In: Progress in physiological psychology, Vol 10 (Sprague JM, Epstein AN, eds), pp 197275. New York: Academic

Gray TS, McMaster SE, I Iarvey JA, Gormezano I (1981) Localization of retractor bulbi motoneurons in the rabbit. Brain Res 226:93-106.

Haley DA, Lavond DG, Thompson RF (1983) Effects of contralateral red nuclear lesions on retention of the classically conditioned nictitating membrane/eyelid response. Soc Neurosci Abstr 9:643.

Haley DA, Thompson RF, Madden J (1988) Pharmacological analysis of the magnocellular red nucleus during classical conditioning of the rabbit nictitating membrane response. Brain Res 454:131-139.

Ito M (1984) The cerebellum and motor control. New York: Raven.

Kandel ER (1976) Cellular basis of behavior. San Francisco: Freeman.

Kelly TM, Zuo CC, Bloedel JR (1990) Classical conditioning of the eyeblink reflex in the decerebrate-decerebellate rabbit. Behav Brain Res 38:7-18.

Kirkpatrick-Steger K, Vander Linden S, Gormezano I (1991) Effects of MDA on classical conditioning of the rabbit nictitating membrane response. Pharmacol Biochem Behav 39:183-189.

Krupa DJ, Weiss C, Thompson RF (1991) Air puff evoked Purkinje cell comlex spike activity is diminished during conditioned responses in eye blink conditioned rabbits. Soc Neurosci Abstr 17:322.

Lavond DG, Steinmetz JE (1989a) An inexpensive interface for IBM $\mathrm{PC} / \mathrm{XT}$ and compatibles. Behav Res Methods Instrum Comput 21: $435-440$.

Lavond DG, Steinmetz JE (1989b) Acquisition of classical conditioning without cerebellar cortex. Behav Brain Res 33:113-164.
Lavond DG, McCormick DA, Clark GA, Holmes DT, Thompson RF (1981) Effects of ipsilateral rostral pontine reticular lesions on retention of classically conditioned nictitating membrane and eyelid response. Physiol Psychol 9:335-339.

Lavond DG, Lincoln JS, McCormick DA, Thompson RF (1984a) Effect of bilateral lesions of the dentate and interpositus cerebellar nuclei on conditioning of heart-rate and nictitating membrane/eyelid responses in the rabbit. Brain Res 305:323-330.

Lavond DG, McCormick DA, Thompson RF (1984b) A nonrecoverable learning deficit. Physiol Psychol 12:103-110.

Lavond DG, Hembree TL, Thompson RF (1985) Effects of kainic acid lesions of the cerebellar interpositus nucleus on eyelid conditioning in the rabbit. Brain Res 326:179-182.

Lavond DG, Steinmetz JE, Yokaitis MH, Thompson RF (1987) Reacquisition of classical conditioning after removal of cerebellar cortex. Exp Brain Res 67:569-593.

Lavond DG, Logan CG, Sohn JH, Garner WDA, Kanzawa SA (1990a) Lesions of the cerebellar interpositus nucleus abolish both nictitating membrane and eyelid EMG conditioned responses. Brain Res 514: 238-248.

Lavond DG, Kanzawa SA, Esquenazi V, Clark RE, Zhang AA (1990h) Effects of cooling interpositus during acquisition of classical conditioning. Soc Neurosci Abstr 16:270.

Lewis JL, LoTurco JJ, Solomon PR (1987) Lesions of the middle cerebellar peduncle disrupt acquisition and retention of the rabbit's classically conditioned nictitating membrane response. Behav Neurosci 101:151-157.

Lincoln JS, McCormick DA, Thompson RF (1982) Ipsilateral cerebellar lesions prevent learning of the classically conditioned nictitating membrane/eyelid response of the rabbit. Brain Res 242:190-193.

Lisberger SG (1984) The latency of pathways containing the site of motor learning in the monkey vestibulo-ocular reflex. Science 225: 74-76.

Logan CG (1991) Cerebellar cortical involvement in excitatory and inhibitory classical conditioning. PhD thesis, Stanford University.

Lye RH, O'Boyle DJ, Ramsden RT, Schady W (1988) Effects of a unilateral cerebellar lesion on the acquisition of eye-blink conditioning in man. J Physiol (Lond) 403:48.

Mamounas LA, Thompson RF, Madden J (1987) Cerebellar GABAergic processes: evidence for critical involvement in a form of simple associative learning in the rabbit. Proc Natl Acad Sci USA 84:2101-2105

Marr D (1969) A theory of cerebellar cortex. J Physiol (Lond) 202: $437-470$.

Mauk MD, Warren JT, Thompson RF (1982) Selective, naloxonereversible morphine depression of learned behavioral and hippocampal responses. Science 216:434-435.

Mauk MD, Steinmetz JE, Thompson RF (1986) Classical conditioning using stimulation of the inferior olive as the unconditioned stimulus. Proc Natl Acad Sci USA 83:5349-5353.

McBride RL, Klemm WR (1968) Stereotaxic atlas of the rabbit brain based on the rapid method of photography of frozen unstained sections. Commun Behav Biol Part A Orig Artic 2:179-215.

McCormick DA, Thompson RF (1984a) Cerebellum: essential involvement in the classically conditioned eyelid response. Science 223 : 296-299.

McCormick DA, Thompson RF (1984b) Neuronal responses of the rabbit cerebellum during acquisition and performance of a classically conditioned nictitating membrane-eyelid response. J Neurosci 4:28112822.

McCormick DA, Lavond DG, Clark GA, Kettner RE, Rising CE, Thompson RF (1981) The engram found? Role of the cerebellum in classical conditioning of nictitating membrane and eyelid responses. Bull Psychon Soc 18:103-105.

McCormick DA, Clark GA, Lavond DG, Thompson RF (1982a) Initial localization of the memory trace for a basic form of learning. Proc Natl Acad Sci USA 79:2731-2742.

McCormick DA, Guyer PE, Thompson RF (1982b) Superior cerebellar peduncle lesions selectively abolish the ipsilateral classically conditioned nictitating membrane/eyelid response of the rabbit. Brain Res 244:347-350.

McCormick DA, Lavond DG, Thompson RF (1982c) Concomitant classical conditioning of the rabbit nictitating membrane and eyelid responses: correlations and implications. Physiol Behav 28:769-775. McCormick DA, Lavond DG, Thompson RF (1983) Neuronal re- 
sponses of the rabbit brainstem during performance of the classically conditioned nictitating membrane (NM)/eyelid response. Brain Res 271:73-88

McCormick DA, Steinmetz JE, Thompson RF (1985) Lesions of the inferior olivary complex cause extinction of the classically conditioned eye blink response. Brain Res 359:120-130.

Millenson JR, Kehoe EJ, Gormezano I (1977) Classical conditioning of the rabbit's nictitating membrane response under fixed and mixed CS-US intervals. Learn Motiv 8:351-366.

Mintz M, Yun Y, Lavond DG, Thompson RF (1988) Unilateral inferior olive NMDA lesions lead to unilateral deficit in acquisition of NMR classical conditioning. Soc Neurosci Abstr 14:783.

Patterson MM, Romano AG (1987) The rabbit in Pavlovian conditioning. In: Classical conditioning, 3d ed (Gormezano I, Prokasy WF, Thompson RF, eds), pp 1-36. Hillsdale, NJ: Erlbaum.

Polenchar BE, Patterson MM, Lavond DG, Thompson RF (1985) Cerebellar lesions abolish an avoidance response in rabbit. Behav Neural Biol 44:221-227.

Port RL, Romano AG, Steinmetz JE, Mikhail AA, Patterson MM (1986) Retention and acquisition of classical trace conditioned response related to interstimulus interval. Behav Neurosci 100:745752.

Powell DA, Buchanan SL, Gibbs CM (1990) Role of the prefrontalthalamic axis in classical conditioning. In: The prefrontal cortex: its structure, function and pathology (Uylings HBM, Van Eden CG, De Bruin JPC, Corner MA, Feenstra MGP, eds), pp 433-466. Amsterdam: Elsevier.

Rescorla RA (1967) Pavlovian conditioning and its proper control procedures. Psychol Rev 74:71-80.

Roscnficld ME; Moore JW (1983) Red nucleus lesions disrupt the classically conditioned nictitating membrane response in rabbits. Behav Brain Res 10:393-398.

Rosenfield ME, Dovydaitis A, Moore JW (1985) Brachium conjunctivum and rubrobulbar tract: brainstem projections of red nucleus essential for the conditioned nictitating membrane response. Physiol Behav 34:751-759.

Sanes JN, Dimitrov B, Hallett M (1990) Motor learning in patients with cerebellar dysfunction. Brain 113:103-120.

Schindler CW, Gormezano I, Harvey JA (1984) Sensory and associative effect of morphine and naloxone in classical conditioning of the rabbit nictitating membrane response. Psychopharmacology (Berl) 83: 114-121.

Schneiderman N (1966) Insterstimulus interval function of the nictitating membrane response in the rabbit under delay versus trace conditioning. J Comp Physiol Psychol 62:397-402.

Schneiderman N, Fuentes I, Gormezano I (1962) Acquisition and extinction of the classically conditioned eyelid response in the albino rabbit. Science 136:650-652.

Sears LL, Steinmetz JE (1990a) Acquisition of classically conditionedrelated activity in the hippocampus is affected by lesions of the cerebellar interpositus nucleus. Behav Neurosci 104:681-692.

Sears LL, Steinmetz JE (1990b) Haloperidol impairs classically conditioned nictitating membrane responses and conditioning-related cerebellar interpositus nucleus activity in rabbits. Pharmacol Biochem Behav 36:821-830.

Sears LL, Steinmetz JE (1991) Dorsal accessory inferior olive activity diminishes during acquisition of the rabbit classically conditioned eyelid response. Brain Res 545:114-122.

Skelton RW (1988) Bilateral cerebellar lesions disrupt conditioned eyelid responses in unrestrained rats. Behav Neurosci 102:586-590.

Smith AM (1970) The effects of rubral lesions and stimulation on conditioned forelimb flexion responses in the cat. Physiol Behav 5:1121-1126.

Solomon PR, Lewis JL, LoTurco JJ, Steinmetz JE, Thompson RF (1986a) The role of the middle cerebellar peduncle in acquisition and retention of the rabbit's classically conditioned nictitating membrane response. Bull Psychon Soc 24:75-78.

Solomon PR, Vander Schaaf ER, Norbe AC, Weisz DJ, Thompson RF (1986b) Hippocampus and trace conditioning of the rabbit's nictitating membrane response. Behav Neurosci 100:729-744.

Solomon PR, Stowe GT, Pendleberry WW (1989) Disrupted eyelid conditioning in a patient with damage to cerebellar afferents. Behav Neurosci 103:898-902.

Steinmetz JE (1990a) Classical nictitating membrane conditioning in rabbits with varying interstimulus intervals and direct activation of cerebellar mossy fibers as the CS. Behav Brain Res 38:91-108.

Steinmetz JE (1990b) Neuronal activity in the rabbit interpositus nucleus during classical NM-conditioning with a pontine-nucleus-stimulation CS. Psychol Sci 1:378-382.

Steinmetz JE, Steinmetz SS (1991) Rabbit classically conditioned eyelid responses fail to reappear after interpositus lesions and extended post lesion training. Soc Neurosci Abstr 17:323.

Steinmetz JE, Thompson RF (1991) Brain substrates of aversive classical conditioning. In: Neurobiology of learning, emotion and affect (Madden J, ed), pp 97-120. New York: Raven.

Steinmetz JE, Rosen DJ, Chapman PF, Lavond DG, Thompson RF (1986) Classical conditioning of the rabbit eyelid response with a mossy fiber stimulation CS. I. Pontine nuclei and middle cerebellar peduncle stimulation. Behav Neurosci 100:871-880.

Steinmetz JE, Logan CG, Rosen DJ, Thompson JK, Lavond DG, Thompson RF (1987) Initial localization of the acoustic conditioned stimulus projection system to the cerebellum essential for classical eyelid conditioning. Proc Natl Acad Sci USA 84:3531-3535.

Steinmetz JE, Lavond DG, Thompson RF (1988) Classical conditioning in rabbits using pontine nucleus stimulation as a conditioned stimulus and inferior olive stimulation as an unconditioned stimulus. Synapse 3:225-233.

Steinmetz JE, Sears LL, Gabriel M, Kubota Y, Poremba A, Kang E (1991) Cerebellar interpositus nucleus lesions disrupt classical nictitating membrane conditioning but not discriminative avoidance learning in rabbits. Behav Brain Res 45:71-80.

Steinmetz JE, Logue SF, Steinmetz SS (in press) Rabbit classically conditioned eyelid responses do not reappear after interpositus nucleus lesion and extensive post-lesion training. Behav Brain Res, in press.

Thach WT, Goodkin HG, Keating JG (1992) The cerebellum and the adaptive coordination of movement. Annu Rev Neurosci 15:403442.

Thompson RF (1990) Neural mechanisms of classical conditioning in mammals. Philos Trans R Soc Lond [Biol] 329:161-170.

Thompson RF, Berger TW, Cegavske CF, Patterson MM, Roemer RA, Teyler TJ, Young RA (1976) The search for the engram. Am Psychol 31:151-161.

Tsukahara N, Oda T, Notsu T (1981) Classical conditioning mediated by the red nucleus in the cat. J Neurosci 1:72-79.

Voneida T, Christie D, Bogdanski R, Chopko B (1990) Changes in instrumentally and classically conditioned limb-flexion responses following inferior olivary lesions and olivocercbcllar tractotomy in the cat. J Neurosci 10:3583-3593.

Walters ET, Byrne JH (1983) Associative conditioning of single sensory neurons suggest a cellular mechanism for learning. Science 219 . 370-374.

Weisz DJ, LoTurco JJ (1988) Reflex facilitation of the nictitating membrane response remains after cerebellar lesions. Behav Neurosci 102:203-209.

Welsh JP (1987) The effect of nucleus interpositus lesions on retention of the rabbit's classically conditioned nictitating membrane response. MA thesis. Iowa City: University of Iowa.

Welsh JP, Harvey JA (1989a) Cerebellar lesions and the nictitating membrane reflex: performance deficits of the conditioned and unconditioned response. J Neurosci 9:299-311.

Welsh JP, Harvey JA (1989b) Intra-cerebellar lidocaine: dissociation of learning from performance. Soc Neurosci Abstr 15:639.

Woodruff-Pak DS, Lavond DG, Thompson RF (1985) Trace conditioning: abolished by cerebellar nuclear lesions but not lateral cerebellar cortex aspirations. Brain Res 348:249-260.

Yeo CH, Hardiman MJ (1988) Loss of conditioned responses following cerebellar cortical lesions is not a performance deficit. Soc Neurosci Abstr 14:3.

Yeo CH, Hardiman MJ, Glickstein M (1985a) Classical conditioning of the nictitating membrane response of the rabbit. I. Lesions of the cerebellar nuclei. Exp Brain Res 60:87-98.

Yeo CH, Hardiman MJ, Glickstein M (1985b) Classical conditioning of the nictitating membrane response of the rabbit. II. Lesions of the cerebellar cortex. Exp Brain Res 60:99-113.

Yeo $\mathrm{CH}$, Hardiman MJ, Glickstein M (1986) Classical conditioning of the nictitating membrane response of the rabbit. IV. Lesions of the inferior olive. Exp Brain Res 63:81-92. 